\title{
La recolocación de monumentos dentro del juego de pelota como mecanismo de activación ritual durante el periodo Clásico maya
}

Le déplacement des monuments dans le cadre du jeu de balle comme mécanisme d'activation rituel pendant la période Classique Maya

The relocation of monuments within the ball game as a ritual activation mechanism during the Maya Classic period

Octavio Quetzalcóatl Esparza Olguín y Rogelio Valencia Rivera

\section{OpenEdition}

\section{Journals}

Edición electrónica

URL: https://journals.openedition.org/jsa/18002

DOI: $10.4000 /$ jsa. 18002

ISSN: 1957-7842

Editor

Société des américanistes

Edición impresa

Fecha de publicación: 30 junio 2020

Paginación: 157-186

ISBN: 978-2-902715-13-8

ISSN: 0037-9174

\section{Referencia electrónica}

Octavio Quetzalcóatl Esparza Olguín y Rogelio Valencia Rivera, «La recolocación de monumentos dentro del juego de pelota como mecanismo de activación ritual durante el periodo Clásico maya», Journal de la Société des américanistes [En línea], 106-1 | 2020, Publicado el 30 junio 2020, consultado el 28 septiembre 2022. URL: http://journals.openedition.org/jsa/18002 ; DOI: https://doi.org/10.4000/ jsa.18002 


\title{
La recolocación de monumentos dentro del juego de pelota como mecanismo de activación ritual durante el periodo Clásico maya
}

\author{
Octavio Quetzalcóatl EsParza Olguín \\ y Rogelio Valencia Rivera*
}

El fenómeno de la recolocación de monumentos, ya estuvieran estos esculpidos o no, durante tiempos prehispánicos en el área maya ha sido documentado por varios investigadores desde las primeras excavaciones arqueológicas de la era moderna, como aquellas efectuadas en Tikal, Cobá o La Milpa durante el siglo pasado. Este empleo de los monumentos de piedra, que posiblemente haya obedecido a múltiples propósitos, en ciertos contextos permite inferir un objetivo predeterminado especial. Tal es el caso de los monumentos hallados recientemente en el sitio de Chactún, descubierto en 2013 y ubicado en el sector norte de la Biósfera de Calakmul, muchos de los cuales fueron seccionados y recolocados en las dos canchas para el juego de pelota detectadas hasta el momento en dicho sitio. La reutilización de estelas, localizadas en posiciones especiales dentro de este contexto arquitectónico, principalmente en sus esquinas y visibles para el espectador, indica que su uso no tenía una finalidad económica o azarosa, en la que los materiales de costosa producción se reutilizarían simplemente para obtener elementos constructivos. En el caso de Chactún, así como en el de otros sitios con contextos similares tales como Calakmul, postulamos que dicho fenómeno debió tener connotaciones diversas, desde un uso práctico cuando los monumentos eran colocados en las esquinas y en el centro de las banquetas, a manera de marcadores de la cancha, hasta una finalidad ceremonial en la que se retomaban el poder y el prestigio de los monolitos para transferirlos al juego de pelota, como parte de su proceso de activación ritual y para posibilitar la práctica de las actividades que debían llevarse a cabo en esos espacios. [Palabras clave: juego de pelota, recolocación de monumentos, estela, activación ritual, uso apotropaico.]

Le déplacement des monuments dans le cadre du jeu de balle comme mécanisme d'activation rituel pendant la période Classique Maya. Le phénomène de réimplantation de monuments, sculptés ou lisses, à l'époque préhispanique dans la région maya, a été largement signalé par plusieurs chercheurs dès les premiers travaux archéologiques de l'ère moderne comme ceux effectués à Tikal, à Cobá ou à La Milpa

* O. Q. Esparza Olguín: Centro de Estudios Mayas, IIFL-UNAM, México, Ciudad de México [ocesol@gmail.com]; R. VALENCIA RIVERA: Investigador independiente, Proyecto Arqueológico Calakmul [rogelio.valencia.rivera@gmail.com]. 
au siècle dernier. Cette réutilisation de monuments en pierre, qui pourrait avoir eu des buts variés, permet de supposer, dans certains cas, une intention prédéterminée spéciale. Il en va ainsi des monuments découverts récemment à Chactún, un site localisé pour la première fois en 2013 dans la partie nord de la Biosphère de Calakmul. Plusieurs ont été découpés et placés dans les deux terrains de jeu de balle détectés à ce jour dans l'établissement. Le placement de stèles en des points très particuliers de ce type de contexte architectural, principalement dans les angles et de façon à être visibles par les spectateurs, semble indiquer que l'enjeu n'était pas économique, avec le réemploi de matériaux coûteux à produire comme simples éléments constructifs, pas plus qu'il ne s'agissait d'un comportement fortuit. Dans le cas de Chactún comme dans ceux d'autres sites dans des contextes identiques, on peut postuler que le phénomène a pu avoir des connotations diverses : depuis un usage pratique quand les monuments en question étaient placés aux angles ou aux centres des banquettes de manière à servir de marqueurs du terrain jusqu'à un rôle symbolique quand il s'agissait de récupérer le pouvoir et le prestige des monolithes pour les transférer aux terrains de jeu dans un processus d'activation rituelle, ce qui rendait possible l'exécution des actes qui devaient se jouer à ces endroits. [Mots-clés : jeu de balle, réimplantation de monuments, stèles, activation rituelle, usage apotropaïque.]

The relocation of monuments within the ball game as a ritual activation mechanism during the Maya Classic period. The monument relocation phenomenon during Prehispanic times in the Maya area, which includes engraved and plain elements, has been documented by various researchers since the realization of the very first archaeological excavations, such as those made during the last century at Tikal, Cobá, and La Milpa. This use of the stone monuments might have served many and varied purposes, but in certain contexts it certainly had a predetermined goal. Such is the case of the monuments recently found at the Maya site of Chactún, discovered in 2013, and located in the Northern sector of the Calakmul Biosphere reserve, as some of them have been found sawn and relocated into two of the ballcourts discovered so far at the site. The reuse of stelae, located at special positions inside this architectonic context, mainly at the corners of the ballcourts and visible to the spectator, indicates that this relocation did not have a random or economical reason, such as reuse of these highly valuable materials as simple construction elements. In the case of Chactún, as well as in similar contexts at other sites such as Calakmul, we propose that this phenomenon had other connotative goals, that went from a practical use of the monuments as ballcourt markers, as they were placed in the corners and at the center of the court, to a ceremonial purpose where the power and prestige of the monuments were taken to be transferred to the newly constructed ballcourt, as part of an apotropaic activation ritual that enabled this constructed space for the practice of the very special ritual activities planned for it. [Keywords: ballgame, monument relocation, stelae, ritual activation, apotropaic use.]

Como resultado de los trabajos arqueológicos implementados en diversos sitios del área maya durante los siglos Xx y XXI, se han documentado un sinnúmero de monumentos esculpidos cuyos textos jeroglíficos nos han permitido adentrarnos 
en la historia de esa fascinante civilización. Asimismo, hemos podido vislumbrar la gran importancia que para los mayas tenía la elaboración y la consagración de objetos tales como estelas, altares y dinteles, como parte esencial de las ceremonias de final de periodo o para la conmemoración de acontecimientos relevantes. Por otra parte, y además del estudio de las inscripciones, el análisis de los contextos asociados a los monumentos ha sido vital para la detección de diversas prácticas rituales, las cuales estaban intrínsecamente relacionadas con los monolitos. Es precisamente entre dichas prácticas que se encuentran vetas de información complementarias a los estudios epigráficos, cuya importancia radica en la inclusión de los elementos materiales que componen el contexto arqueológico, como parte fundamental dentro del estudio de los monumentos. Una de esas vetas corresponde a un fenómeno que ha sido documentado ampliamente en diversos sitios del área maya: la recolocación de monumentos,

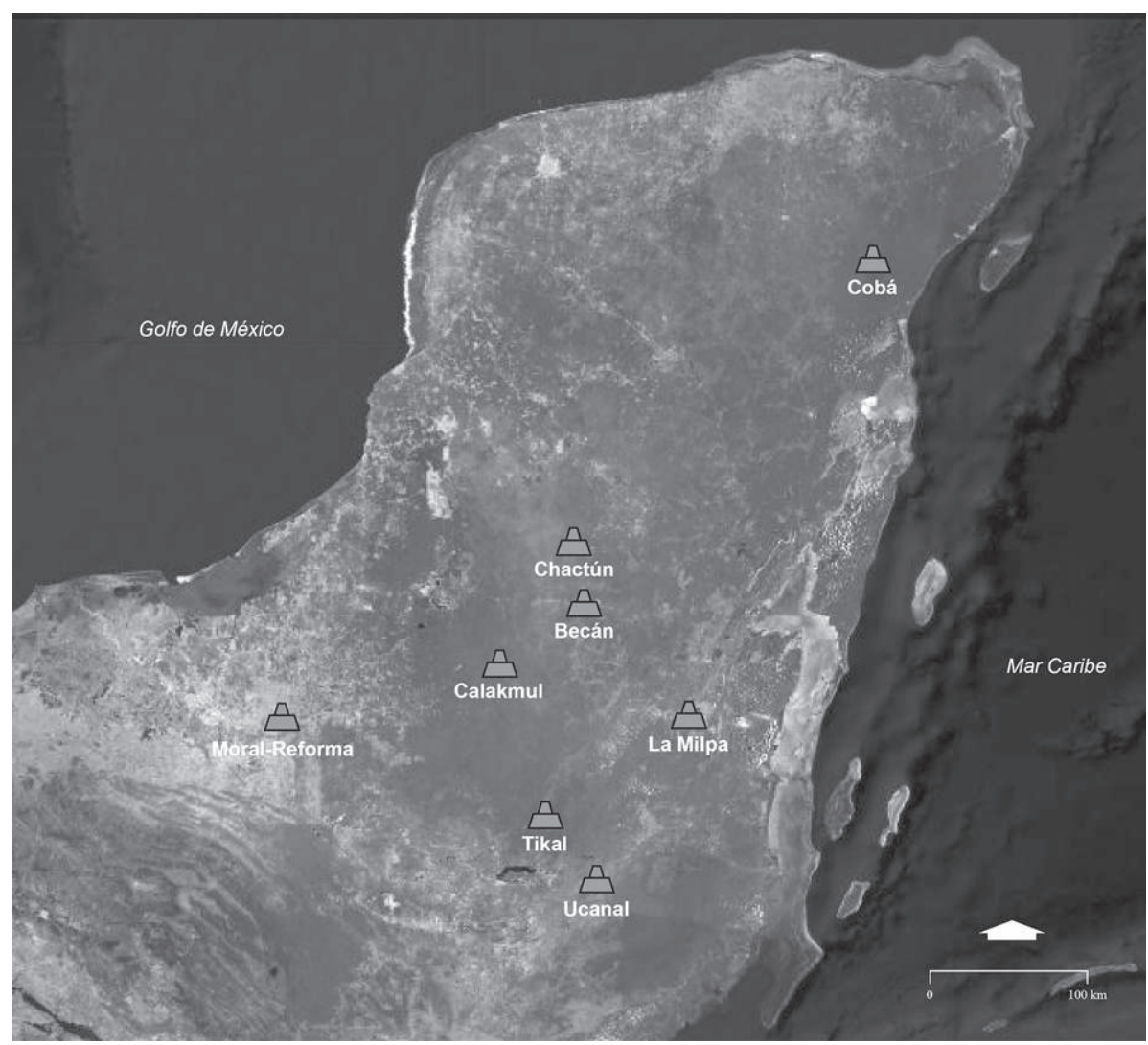

Fig. 1 - Mapa de ubicación de diversos sitios donde se ha registrado el fenómeno de la recolocación de monumentos (imagen modificada de Google Earth/Digital Globe (C), 2018). 
ritual asociado directamente con la gran importancia y prestigio que revestían los monolitos, tanto lisos como esculpidos, para los mayas del periodo Clásico (Houston y Stuart 1998; O’Neil 2013; Stuart 1996 y 2010).

Debido a que la reutilización de los monolitos fue detectada en el área maya desde épocas tempranas de la investigación arqueológica y a que no se encuentra ligado de forma exclusiva al juego de pelota, resulta conveniente mencionar algunos antecedentes sobre su hallazgo y los diferentes contextos en que puede encontrarse. Esta información también permitirá establecer las similitudes y diferencias detectadas en diversos asentamientos donde se ha registrado el proceso de recolocación.

\section{Antecedentes}

El primer asentamiento donde se documentó la presencia de contextos relacionados con la reubicación de monumentos lisos y esculpidos fue Cobá. Este enorme sitio, localizado en el extremo noreste de la península de Yucatán, comenzó a estudiarse de forma sistemática durante la década de 1920, por parte de la Carnegie Institution of Washington, entre cuyos especialistas se encontraban Sylvanus Morley, Harry Pollock y Eric Thompson. Su interés en Cobá se generó por la presencia de una importante cantidad de monumentos esculpidos hallados en diversos sectores del asentamiento, destacándose por su número y por su estado de conservación aquellos descubiertos en el Grupo Macanxoc (Morley 1927; Pollock 1932; Thompson, Pollock y Charlot 1932).

Fue precisamente durante el estudio de las estelas localizadas en dicho grupo, que Sylvanus Morley y Harry Pollock notaron su asociación con elementos arquitectónicos tardíos, entre los que figuraban templos del estilo Costa Oriental, de manufactura posclásica, así como pequeños santuarios (shrine) que contenían monumentos completos o fragmentos de estos. Estas características, en conjunción con las fechas tempranas registradas en las estelas, los llevaron a plantear la hipótesis de que se trataba de monumentos recolocados, es decir, piezas que habían sido retiradas de sus localizaciones originales para ser ubicadas en el Grupo Macanxoc por parte de los mismos pobladores del asentamiento, en una época posterior a la de su erección. Al respecto, Morley comenta:

The style of architecture of the buildings and terraces at Macanxoc is so late, that there can be little doubt that these monuments were originally designed for some other locations. (Morley 2006, p. 555)

Por su parte, Pollock expresa una opinión muy concreta respecto a las pequeñas edificaciones que contienen muchas de las estelas:

These structures gain their name from apparently having been erected for the express purpose of enclosing stelae [...] as far as is known the stelae shrine is a type of structure peculiar to this area. In all other places that stelae occur they are found outside of buildings. Taking into consideration the fact that these stelae are 
located at a site where there are definite traces of a much later occupation (East Coast) than the period represented by the early dates on the monuments, this new departure in the placing of stelae inside of buildings makes one strongly suspect that they have been relocated in their present positions. (Pollock 1932, p. 114)

Tiempo después de los trabajos de la Carnegie Institution of Washington en Cobá, se descubrieron en otros sitios contextos arqueológicos que indicaban la presencia de procesos de recolocación. Uno de los sitios donde se documentó dicho fenómeno de forma muy puntual fue Tikal (Satterthwaite 1986) y sus alrededores (Martin 2000), donde los investigadores de la Universidad de Pennsylvania reportaron diversos contextos "anormales" que estaban relacionados con segmentos de estelas. En este caso, Linton Satterthwaite (1986) registró casi una decena de contextos donde se hallaron porciones superiores o inferiores de estelas con restos de grabado, formulando diversas hipótesis para tratar de explicar este fenómeno, entre las que se encuentra su aplicación con fines ceremoniales o como resultado de actividades hostiles relacionadas con conflictos bélicos. El mismo Satterthwaite plantea que, sobre la base de la información proveniente del contexto arqueológico, el proceso de recolocación de muchas de las estelas de Tikal debió realizarse durante el Clásico Tardío.

Otro asentamiento para considerar es La Milpa, Belice, donde ya desde la década de 1930 Eric Thompson documentó la presencia de un importante número de estelas (Hammond y Bobo 1994; Hammond y Tourtellot 2006). En este caso, fue a finales de la centuria pasada que, por medio de diversos trabajos de prospección y de excavación, se pudo establecer que algunos monumentos correspondían a fragmentos de estelas que habían sido re-erigidas, principalmente en la Gran Plaza frente a la Estructura 1. Por medio del contexto arqueológico, se determinó que el proceso de recolocación de las estelas debió llevarse a cabo durante el periodo Clásico Terminal o bien en el Posclásico Temprano (Hammond y Bobo 1994).

Asimismo, en Chactún también se documentó el proceso de recolocación en otros espacios además del de juego de pelota, que consiste en la erección de fragmentos superiores o inferiores de estelas lisas o grabadas frente a grandes montículos y en espacios abiertos como patios y plazas. Un caso de características muy peculiares es el de la Estela 14, monolito esculpido que fue embebido casi en su totalidad dentro de una gran plataforma ubicada en el extremo noroeste del Complejo Sureste, donde tan solo se dejó expuesta una pequeña parte de su sección superior (Esparza Olguín 2015). Durante el proceso de liberación pudo constatarse que el monumento contenía un texto jeroglífico bien conservado, así como la efigie de un gobernante local que fue plasmada mediante el uso de estuco modelado y pintado $^{1}$.

1. Otros ejemplos del proceso de recolocación se encuentran documentados en sitios de diversas regiones del área maya, como es el caso de El Resbalón y Dzibanché en el sur de Quintana Roo (Walters 1978; Nalda Hernández 2004; Tsukamoto 2005; Esparza Olguín 2012 
Como puede observarse, la mayor parte de los ejemplos documentados corresponden a la recolocación de fragmentos de monolitos, sobre todo estelas, que fueron re-erigidos en espacios ocultos o bien a plena vista frente a basamentos piramidales y en las grandes plazas. Esta característica resulta interesante, ya que en el caso específico del juego de pelota los mayas retomaron esta misma práctica, colocando fragmentos de estelas y otro tipo de monumentos en lugares específicos y puntuales de la cancha, tales como las esquinas y la parte central de las banquetas, lo que a nuestro entender imposibilita el hecho de que hayan sido utilizados como material meramente constructivo.

Ya identificadas las características generales del proceso de recolocación, explicaremos ahora el contexto específico en que fueron hallados los monumentos reutilizados en los juegos de pelota de Chactún, así como su semejanza con otros casos de estudio.

\section{Chactún, sus juegos de pelota y contextos similares}

Chactún fue descubierto durante la temporada de campo del año 2013 del Proyecto de Reconocimiento Arqueológico en el Sureste del Estado de Campeche (PRASEC). El sitio se encuentra constituido por tres grandes grupos arquitectónicos denominados como complejos A (Oeste), B (Sureste) y C (Noreste), que exhiben arquitectura monumental (Šprajc 2015). Los dos primeros cuentan con sendas canchas de juego de pelota donde se detectaron grandes bloques de piedra ubicados en las esquinas de las banquetas (Figuras 2 a y 2b). Como consecuencia de este hallazgo, se decidió liberar dichos bloques, para poder apreciar de mejor manera sus características y establecer si se trataban de monumentos grabados o, simplemente, de piedras lisas. Una vez concluido el trabajo de excavación, pudimos constatar que los bloques correspondían a fragmentos de estelas grabadas y lisas.

De esta forma, en el juego de pelota del Complejo Sureste, fueron identificados en total cuatro fragmentos, de los cuales uno correspondía a la sección inferior de una estela (Estela 17), otro a la sección superior (Estela 19) y dos más al cuerpo de un tercer monumento (Estela 18): Figura 2b. Dentro de esta misma cancha se descubrió un quinto bloque de mayores dimensiones, cuya superficie no mostraba ningún tipo de grabado, y que bien podría corresponder a una estela lisa.

\footnotetext{
y 2016), así como Ucanal, Naranjo y Xunantunich en la zona del Petén (Graham 1978; Martin y Grube 2002; Helmke y Awe 2016a y 2016b). Resulta interesante que en todos estos asentamientos muchos de los monumentos recolocados corresponden a bloques de escalinatas jeroglíficas: tal es el caso de la Escalera Jeroglífica II de El Resbalón, de la escalinata del Edificio de los Cautivos de Dzibanché y de la escalera jeroglífica de Caracol, cuyos bloques terminaron diseminados en asentamientos como Xunantunich, Ucanal y Naranjo.
} 
El juego de pelota como mecanismo de activación ritual

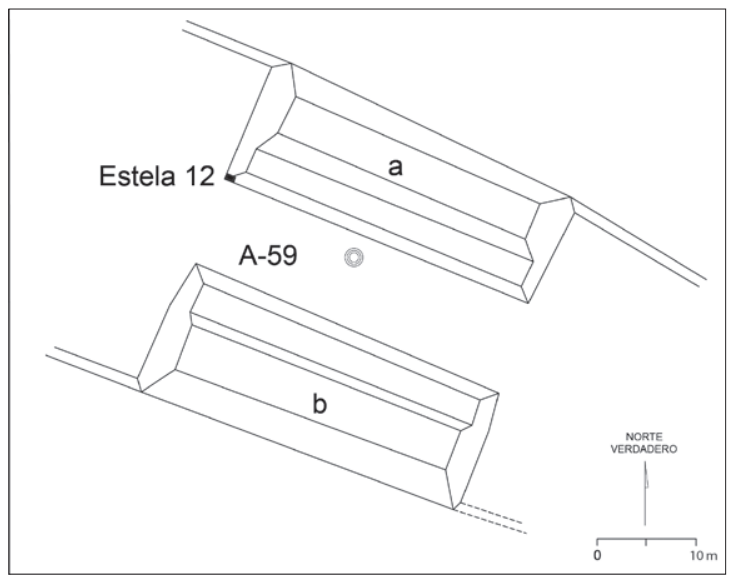

Fig. 2a - La cancha de juego de pelota del Complejo Oeste de Chactún (modificado de Šprajc et al. 2015).

Fig. 2b - La cancha de juego de pelota del Complejo Sureste de Chactún (modificado de Šprajc et al. 2015).

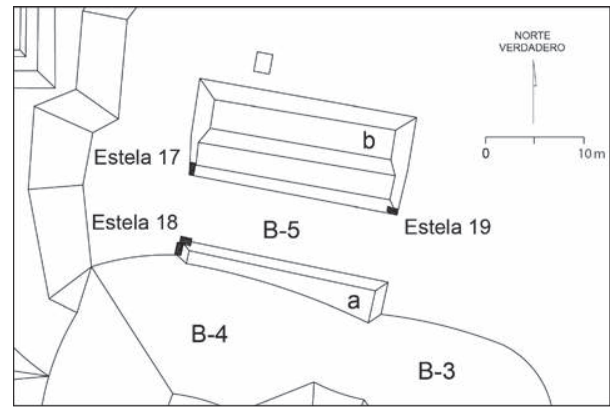

\section{Estela 17}

Con unas dimensiones de 1,18 $\mathrm{m}$ de largo, 0,74 $\mathrm{m}$ de ancho y 0,48 $\mathrm{m}$ de grosor, fue localizada en el extremo suroeste de la Estructura B-5b (Figura 3). Se trata del fragmento inferior de un monumento con restos de grabado en su cara frontal y en ambos costados. Aunque el texto jeroglífico y la imagen plasmados en la estela se encontraron en un avanzado estado de deterioro, fue posible identificar las extremidades inferiores de una figura antropomorfa (muy probablemente de un gobernante local) colocadas sobre un elemento de forma trilobulada. Este último rasgo ha sido identificado previamente en otros monumentos del área maya, como en aquellos del sitio de Machaquilá (estelas 4, 7 y 8), y se encuentra relacionado con la representación de espacios restringidos, donde se realizaban rituales que, probablemente, solo podían ser apreciados por personajes de la élite social, política y religiosa del señorío (Stuart y Houston 1994; Houston et al. 2005; Lacadena García-Gallo 2011). Asimismo, se detectó la presencia de una fecha de Rueda Calendárica 4 ajaw 13 yax, que debe corresponder al final del decimoquinto k'atuun, acaecido en 9.15.0.0.0 (18 de agosto de $731 \mathrm{~d}$. C.), tomando en cuenta que todas las fechas 


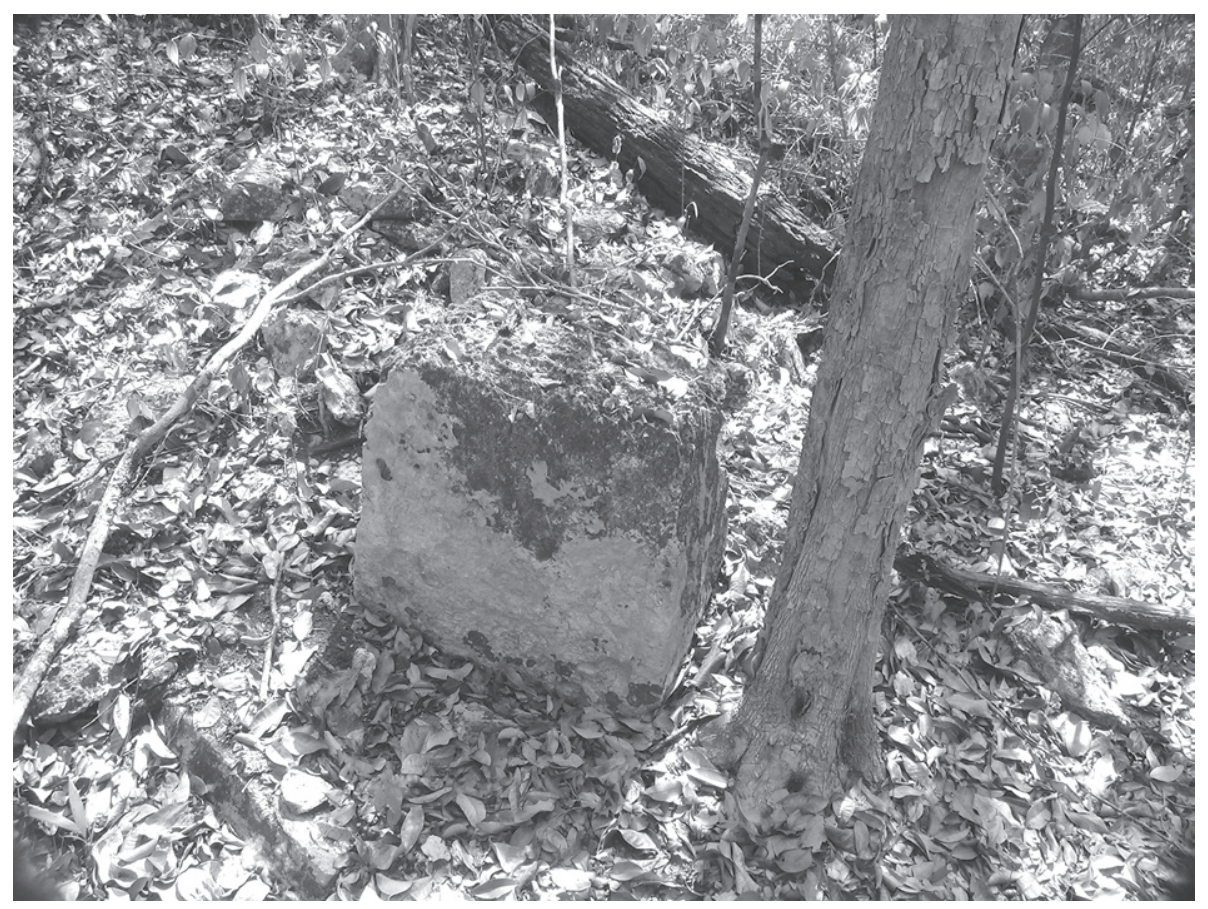

Fig. 3 - Fragmento inferior de la Estela 17 en el momento de su descubrimiento (fotografía O. Esparza, PRASEC).

registradas hasta el momento en los monumentos de Chactún corresponden a la primera mitad del siglo viII d. C.

Por otra parte, resulta importante señalar que durante el proceso de liberación de la estela se detectó la presencia de un conjunto de 304 lascas de pedernal, que fue colocado frente a la superficie del costado derecho del monumento (Figura 4). Las lascas fueron depositadas justo sobre un piso de estuco y corresponden a una ofrenda tardía del Posclásico o del Clásico Terminal, lo que implica que la estela fue objeto de culto aun fragmentada y en un momento muy posterior al de su hechura, dejando de manifiesto la importancia que mantenían los monumentos esculpidos, aunque hubieran sido seccionados y recolocados.

\section{Estela 18}

Se encontró rota en dos fragmentos y conformando la esquina noroeste de la Estructura B-5a. En un principio solo se había detectado parte de la sección inferior del monumento, en la cual no se apreciaban restos de textos o imágenes. Fue durante el proceso de liberación que nos percatamos de la presencia de un segundo fragmento y de diversos elementos grabados en la superficie de ambos 


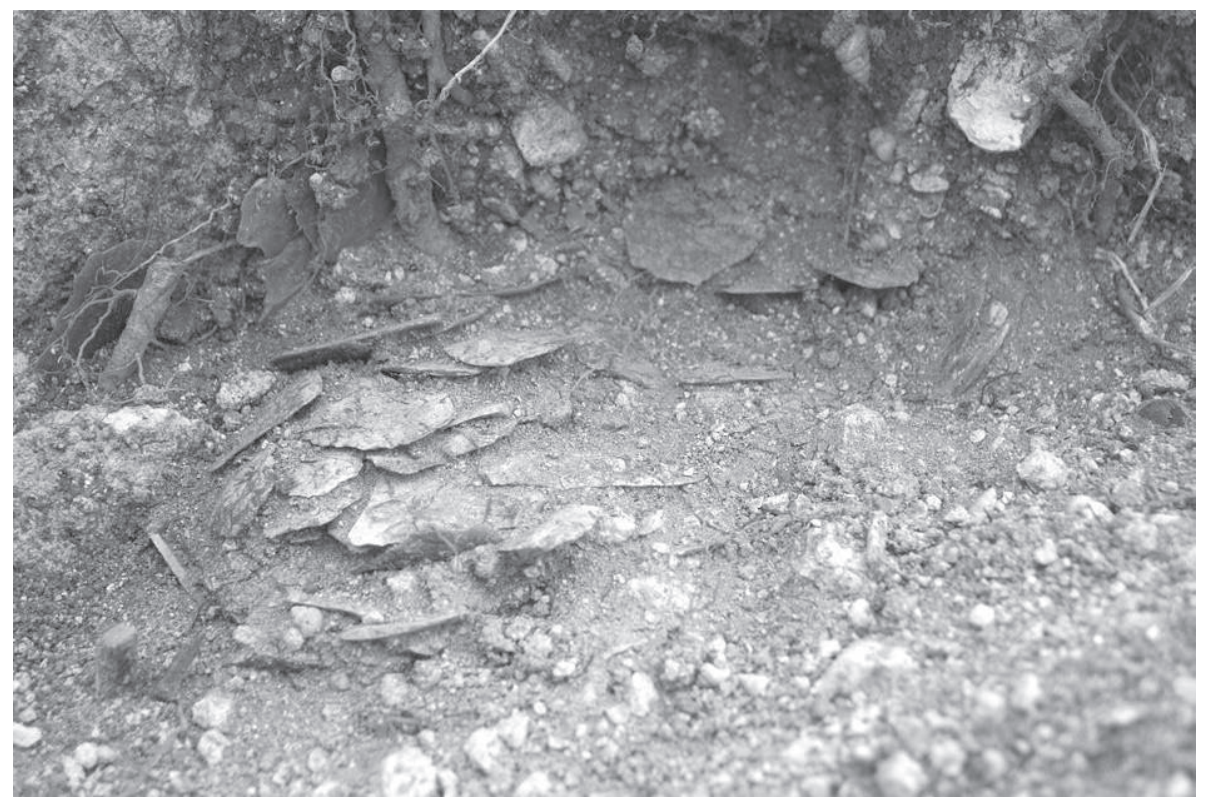

Fig. 4 - Lascas de pedernal localizadas en un costado de la Estela 17 (fotografía O. Esparza, PRASEC).

bloques, comprobando de igual forma que estos habían sido colocados a manera de escuadra, dejando constancia de su re-uso como un elemento arquitectónico dentro de la cancha de juego de pelota (Figura 5, página siguiente). Una vez liberados los fragmentos, pudo constatarse que formaban parte de una misma estela (Figura 6a, página siguiente), que había sido grabada en sus cuatro lados, contando con la representación de figuras antropomorfas en las caras frontal y posterior, así como de textos jeroglíficos en los costados.

Las imágenes plasmadas en el monumento corresponden a las de dos personajes de pie y ricamente ataviados (Figura 6b, páginas siguientes); portan grandes tocados, así como orejeras, pectorales, muñequeras, bragueros y sandalias. En el aspecto epigráfico, se tiene el registro de una fecha de Cuenta Larga 9.15.0.0.0 (18 de agosto de 731 d. C.), en combinación con diversos cómputos de la Serie Suplementaria. Lamentablemente, no contamos con ningún verbo ni cláusula nominal dentro de la inscripción, aunque resulta obvio que la estela fue erigida para conmemorar el final del decimoquinto $k$ 'atuun (Figura 6b).

Un hecho relevante que pudo detectarse al unir ambos fragmentos es que la ruptura de la estela debió efectuarse de forma intencional, ya que el patrón de corte es muy regular y dividió casi por la mitad al monumento. Este acto deliberado indica que esta estela fue elegida de antemano para ser integrada como parte del material constructivo de la cancha, y no como una estrategia derivada del quiebre accidental del monolito después de su erección. 


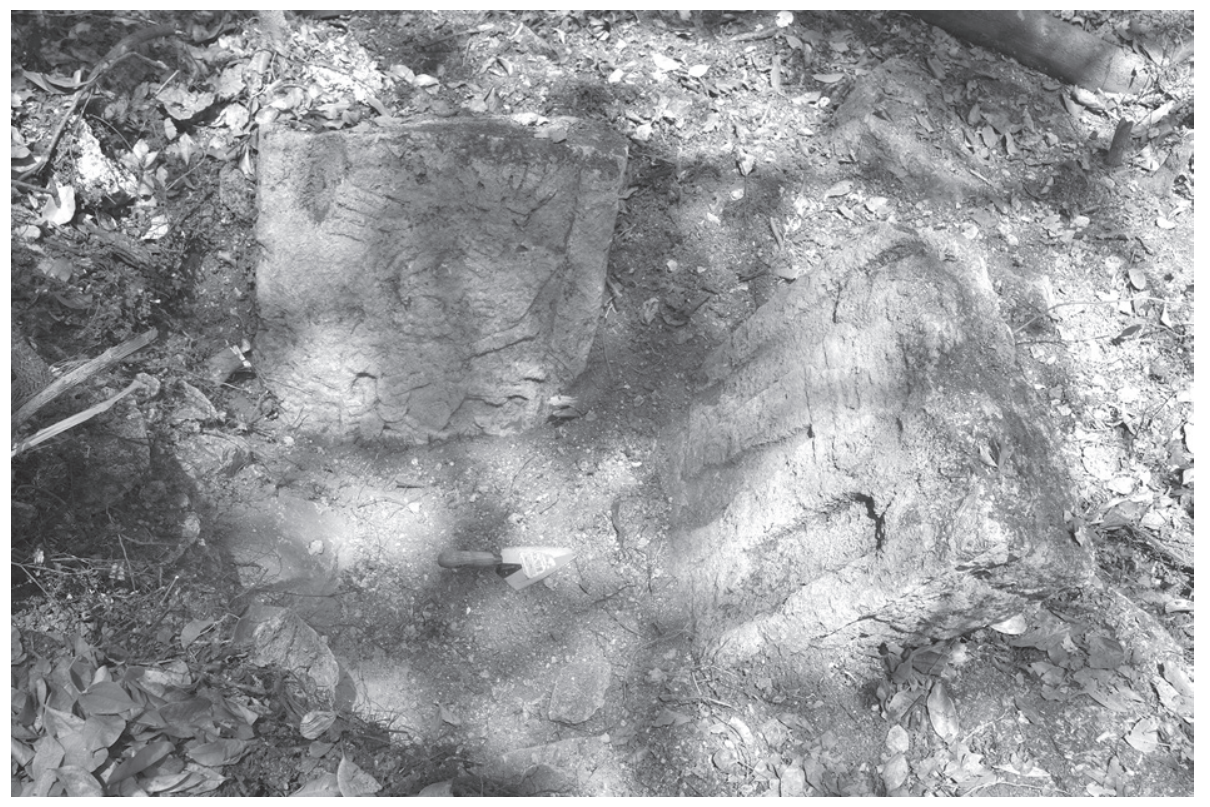

Fig. 5 - Proceso de liberación de la Estela 18

(fotografía O. Esparza, PRASEC).

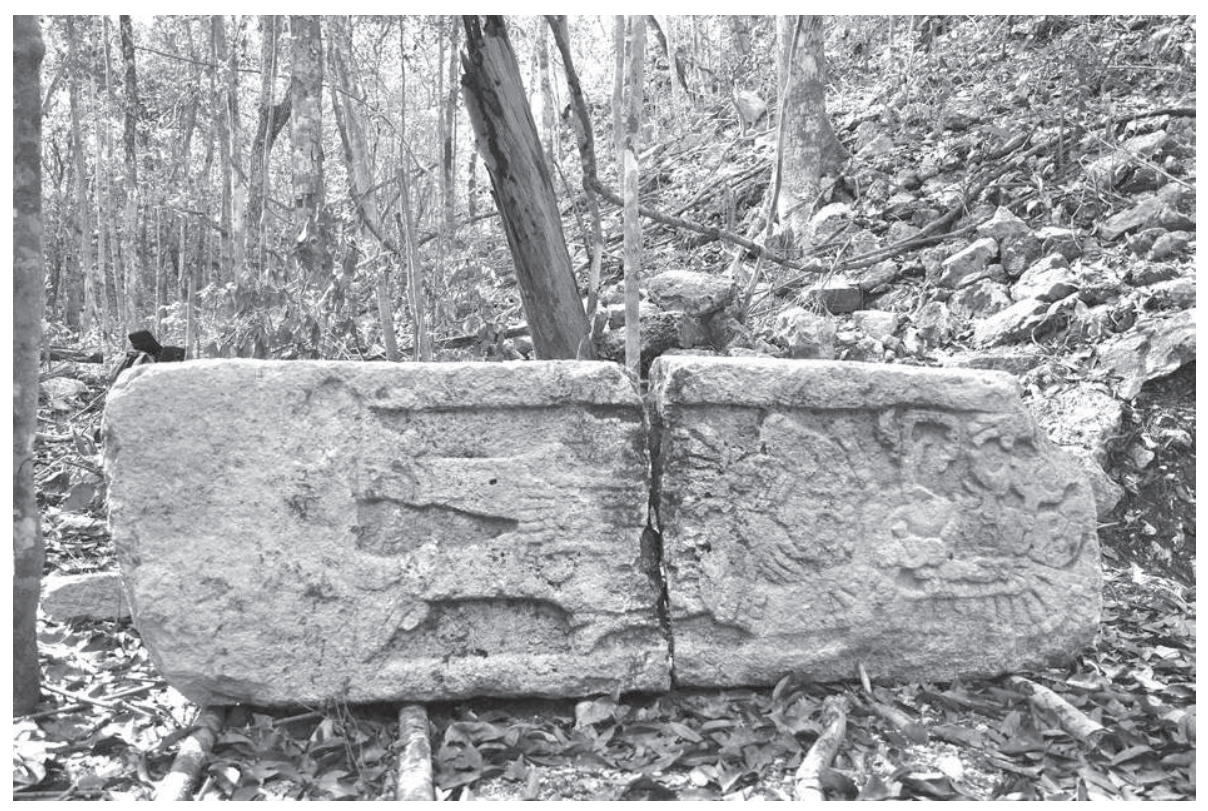

Fig. 6a - Estela 18 una vez unidos los dos fragmentos que la conforman (fotografía O. Esparza, PRASEC). 


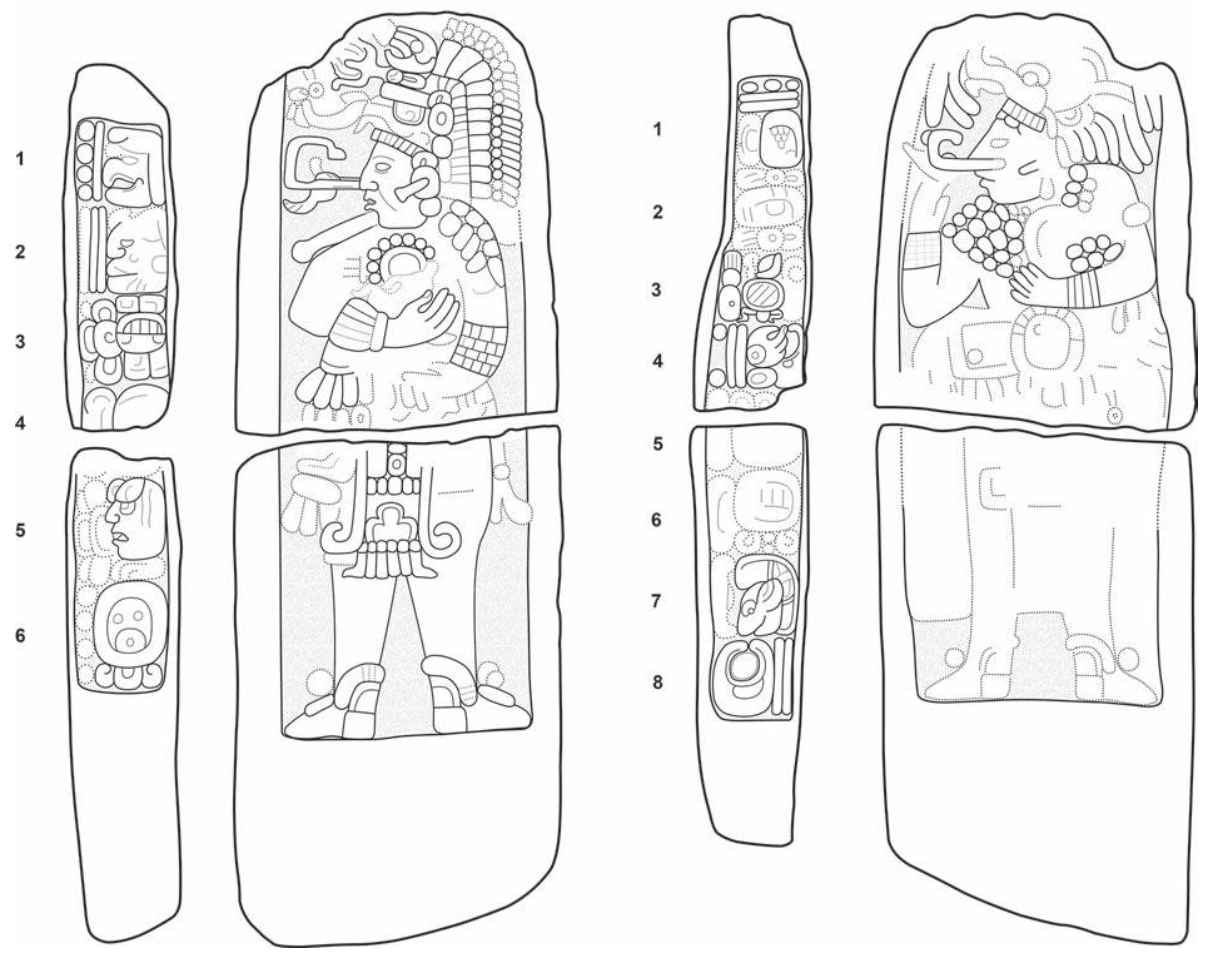

Fig. $6 \mathrm{~b}$ - Dibujo del monumento donde se aprecia el grabado de sus cuatro caras (dibujo O. Esparza, PRASEC).

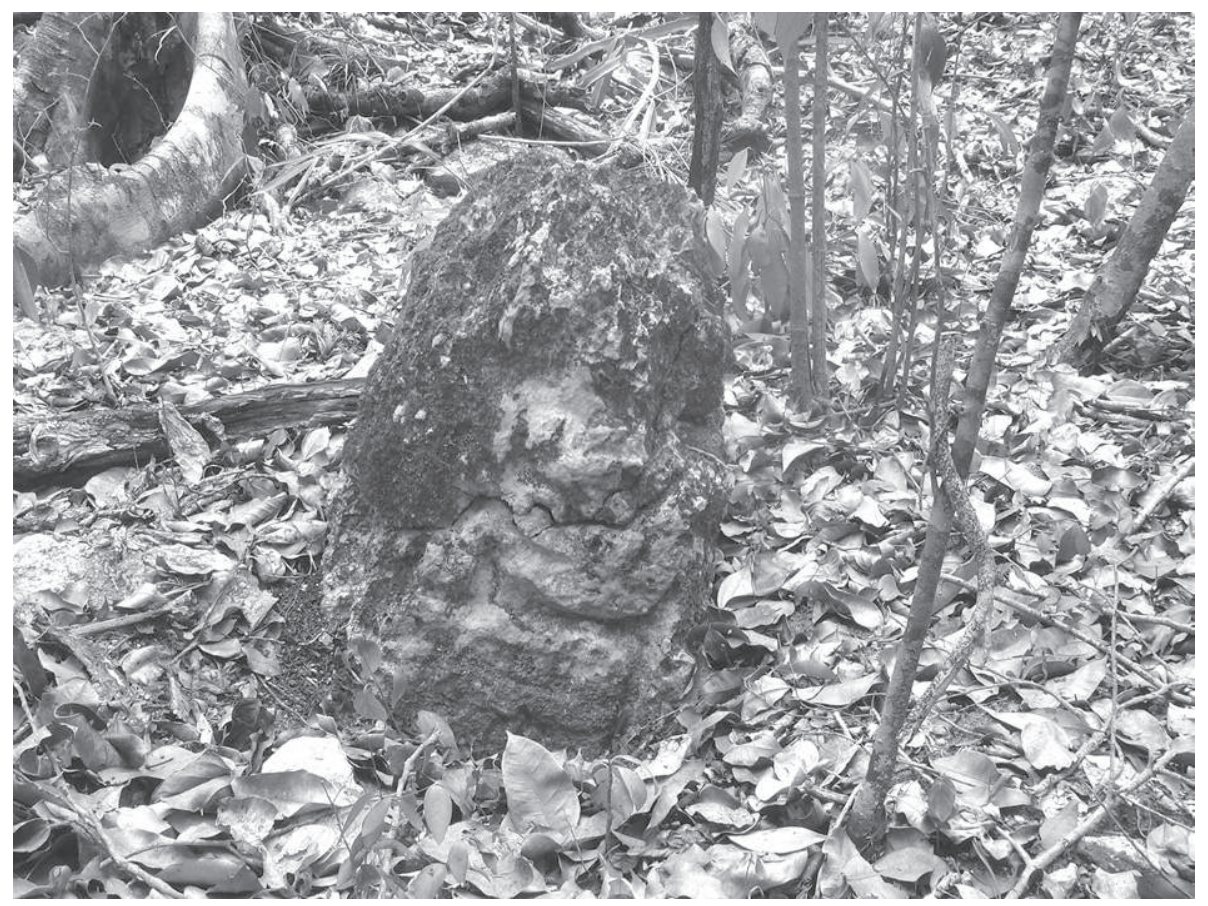

Fig. 7 - Fragmento superior de la Estela 19 en el momento de su descubrimiento (fotografía O. Esparza, PRASEC). 


\section{Estela 19}

Fue descubierta en la esquina sureste de la Estructura B-5b y corresponde a la sección superior del monumento. En el momento de su hallazgo presentaba un avanzado estado de deterioro, distinguiéndose tan solo parte de un texto jeroglífico esculpido en el costado izquierdo, que corresponde al registro de una fecha en el sistema de Cuenta Larga (Figura 7, página anterior). Lamentablemente, el grado de erosión del fragmento no permite identificar plenamente todos los periodos calendáricos.

\section{Estela 12}

Como se comentó con antelación, también en el Complejo Oeste detectamos una cancha de juego de pelota, donde yacía un fragmento de estela en el extremo suroeste de la Estructura A-59a (Figura 2a). El monumento fue hallado durante las labores de recorrido implementadas en el sector sureste de dicho complejo, encontrándose prácticamente cubierto por el escombro y la vegetación. Una vez liberado (Figura 8), pudimos apreciar que se trataba del fragmento superior y que tenía grabada parte de una fecha de Cuenta Larga que, al parecer, está relacionada con el final del decimosexto $k$ 'atuun en 9.16.0.0.0 (5 de mayo de 751 d. C.). De igual forma, contiene el registro de un ciclo de 819 días, referencia única hallada en una inscripción del sur de Campeche. En el aspecto iconográfico, se aprecia el rostro y el tocado de un personaje, asociados a la figura de una serpiente fantástica similar a las que pueden observarse en los dinteles 15 y 25 de Yaxchilán (Figura 9).

A diferencia de la Estela 18, el fragmento que nos ocupa fue grabado en tres de sus caras, quedando la superficie posterior lisa. Este hecho es relevante, ya que presentaba la opción de poder colocar la piedra con el grabado en el interior de la banqueta, o bien en el exterior para exhibir la imagen, siendo esta última la decisión adoptada por los constructores de la cancha, indicando que la parte labrada del monumento posee un valor diferencial e importante dentro del proceso de recolocación. Por último, hay que hacer notar que la piedra fue colocada de cabeza, es decir, con el texto jeroglífico y los elementos iconográficos al revés.

Resulta toda una interrogante si, al igual que el juego de pelota del Complejo Sureste, este también ostentó monumentos fragmentados y recolocados en sus cuatro esquinas, lo que tan solo podrá ser revelado a partir de futuros trabajos arqueológicos en el sitio. Sin duda, los hallazgos de Chactún resultan de gran relevancia dentro de la discusión del fenómeno de la recolocación de monumentos, ya que además de aportar información novedosa se relacionan con contextos escasamente documentados en otros asentamientos del área maya, donde la ubicación de fragmentos de estelas u otro tipo de monolitos en las 
El juego de pelota como mecanismo de activación ritual

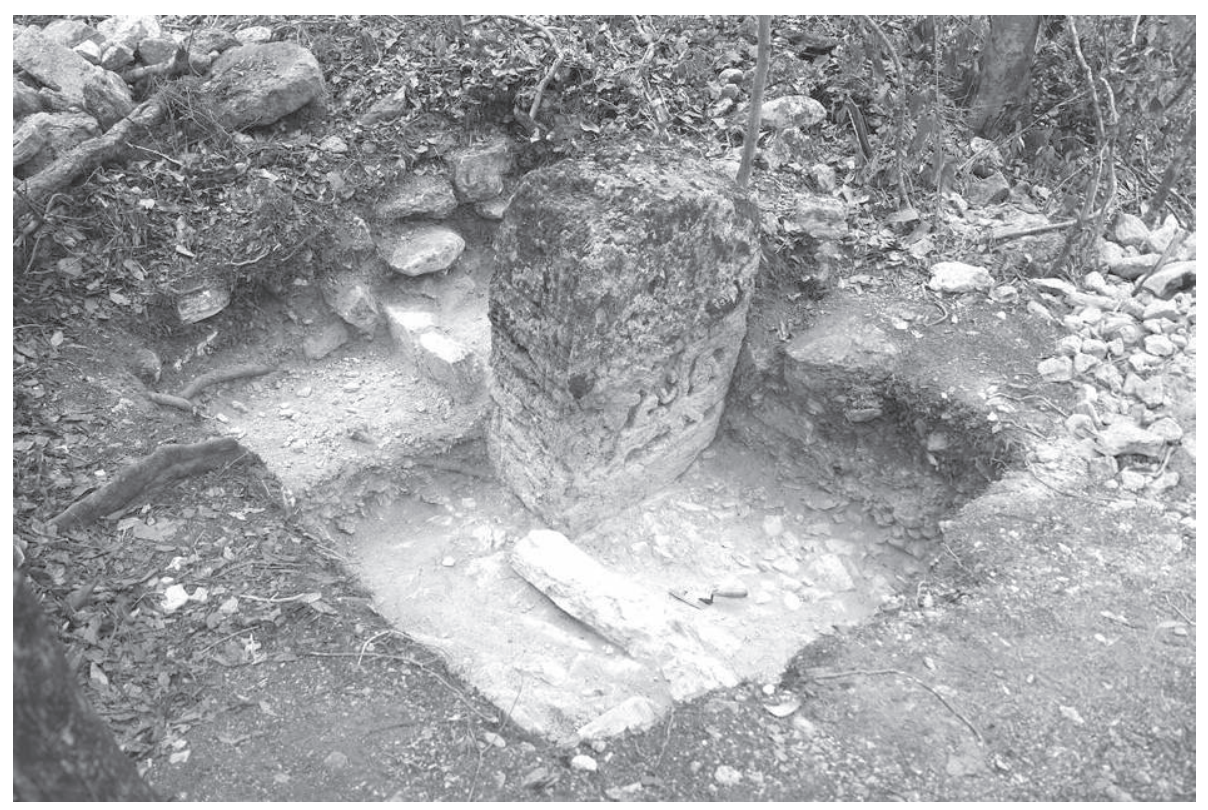

Fig. 8 - Proceso de liberación de la Estela 12

(fotografía O. Esparza, PRASEC).

C D

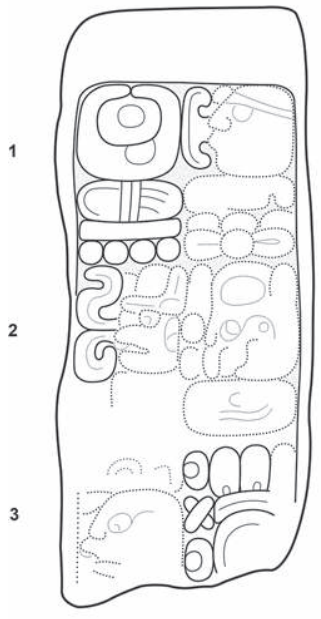

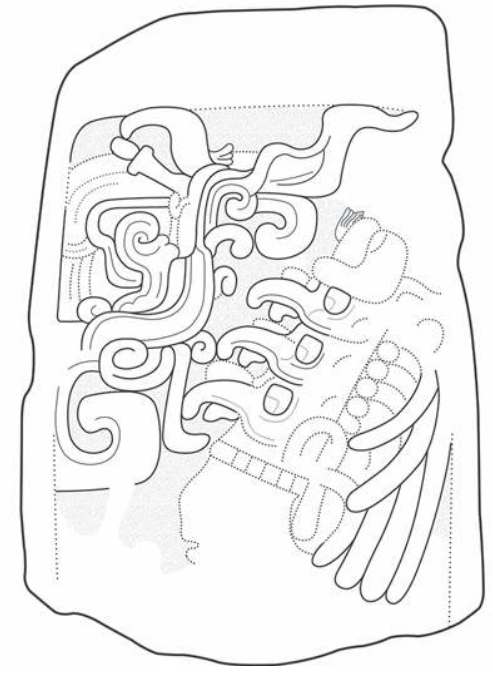

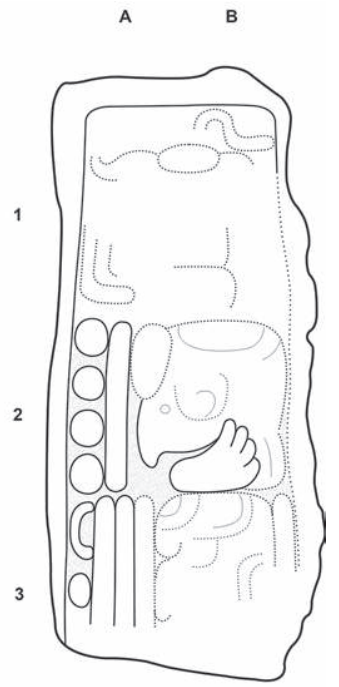

Fig. 9 - Elementos grabados en la superficie de la Estela 12 (dibujo O. Esparza, PRASEC). 
esquinas de las banquetas resulta inusual. En este caso, resalta por su similitud la Estructura XI de Calakmul, cuyo análisis resultará útil para comprender de mejor manera los procesos de recolocación observados en Chactún.

\section{El juego de pelota de Calakmul}

La cancha de juego de pelota de esta ciudad, denominada oficialmente como la Estructura XI, tuvo una gran relevancia histórica al ser mencionada directamente en algunos textos del Clásico Tardío (600 al 950 d. C.) y que ya fue reportada por Ruppert y Denison durante su exploración del sitio (1943, p. 21; Figura 10).

El juego de pelota de Calakmul es una estructura formada por dos edificios paralelos, cada uno de los cuales cuenta con una plataforma en talud que termina en un paramento vertical. Datada para el Clásico Temprano (200-600 d. C.), gracias al análisis del material cerámico obtenido de un pozo estratigráfico practicado en la parte central del cuerpo este (González 1996, p. 74), sus dimensiones son de 20,14 $\mathrm{m}$ de largo por 8,66 $\mathrm{m}$ de ancho, para cada uno de sus edificios paralelos. La plataforma en talud tiene una altura de $79 \mathrm{~cm}$ en su parte más alta y una anchura de 3,81 m mientras que el paramento vertical mide $65 \mathrm{~cm}$ de alto (Carrasco Vargas et al. 1996, p. 85). El basamento del lado oeste cuenta asimismo con una escalinata en su parte central posterior. En cambio, el basamento del lado oriental cuenta con dos escalinatas ubicadas hacia sus extremos norte y sur. Durante la excavación de esta estructura, por parte del Proyecto Arqueológico Calakmul (PAC) a cargo del arqueólogo Ramón Carrasco, fueron localizados en su interior diez monumentos de piedra inscritos y/o esculpidos (Figura 11), cuatro de los cuales estaban originalmente localizados en las esquinas de ambos basamentos del edificio (Andrews 1995, p. 79-81; Carrasco Vargas et al. 1996, p. 82; González 1996, p. 74), aunque uno se encontraba desplazado de su localización original debido al derrumbe parcial de la esquina noroeste del basamento.

Los tres fragmentos de piedra labrada localizados en las esquinas de la cancha de la Estructura XI originalmente pertenecían a un único monumento, la Estela 66, que fue dividido en aproximadamente tres partes iguales de forma deliberada, pues sus cortes son perpendiculares al eje de la estela, de manera similar a como ocurre con la Estela 18 de Chactún, y a la que se le sumaría un trozo de otro monumento inscrito. La fotografía de la estela ensamblada puede apreciarse en la Figura 12 (páginas siguientes) y su dibujo se encuentra en la Figura 13 (páginas siguientes).

La estela contiene un texto en su lado derecho que se lee (Figura 13: B1-B6): yo-OL-la ?-? ?-15?-HAB-ta i-u-ti 4 AJAW, yohl ... 15? haab ta iuhti 4 ajaw, lo cual podría indicar la fecha de Cuenta Larga 9.15.0.0.0, 4 ajaw 13 yax (18 de agosto de 731 d. C.) (Carrasco Vargas et al. 1996, p. 80), lo que la 
El juego de pelota como mecanismo de activación ritual
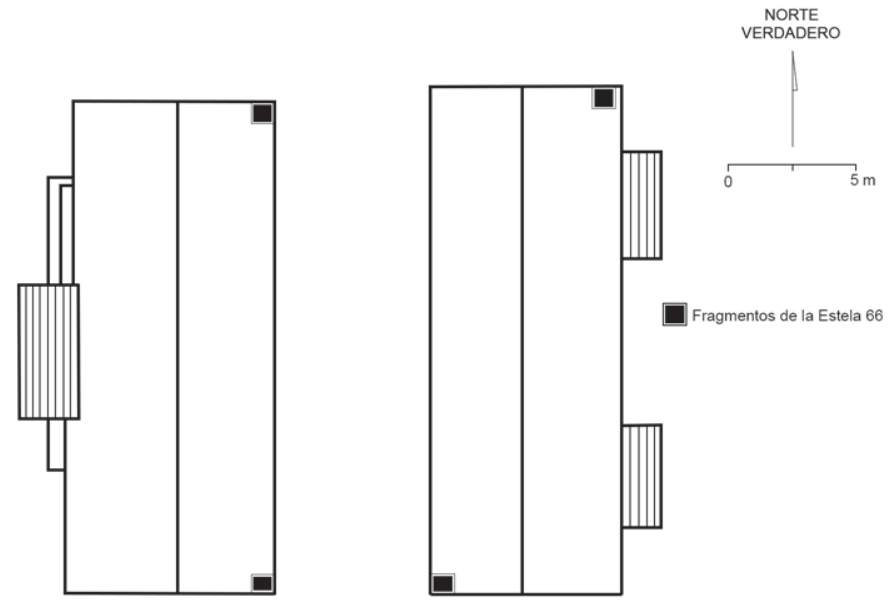

Fig. 10 - Estructura XI o Juego de Pelota de Calakmul. El plano muestra dónde estaban ubicados los trozos de la Estela 66 (Carrasco Vargas et al. 1996, p. 88).

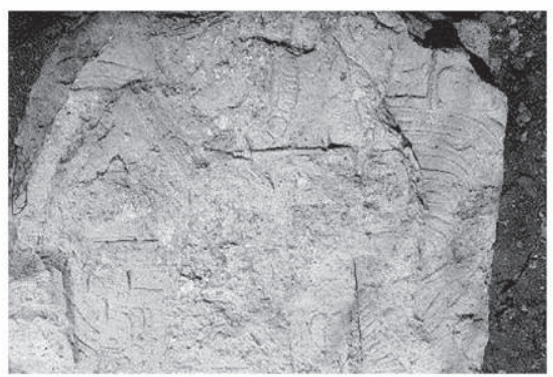

a

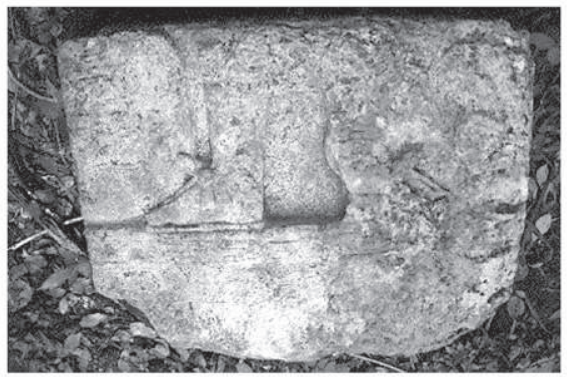

b

Fig. 11 - Fotografía de dos de los trozos de la Estela 66 tal y como fueron hallados en el Juego de Pelota de Calakmul (fotografía Omar Rodríguez, PAC). 
Octavio Quetzalcóatl Esparza Olguín y Rogelio Valencia Rivera

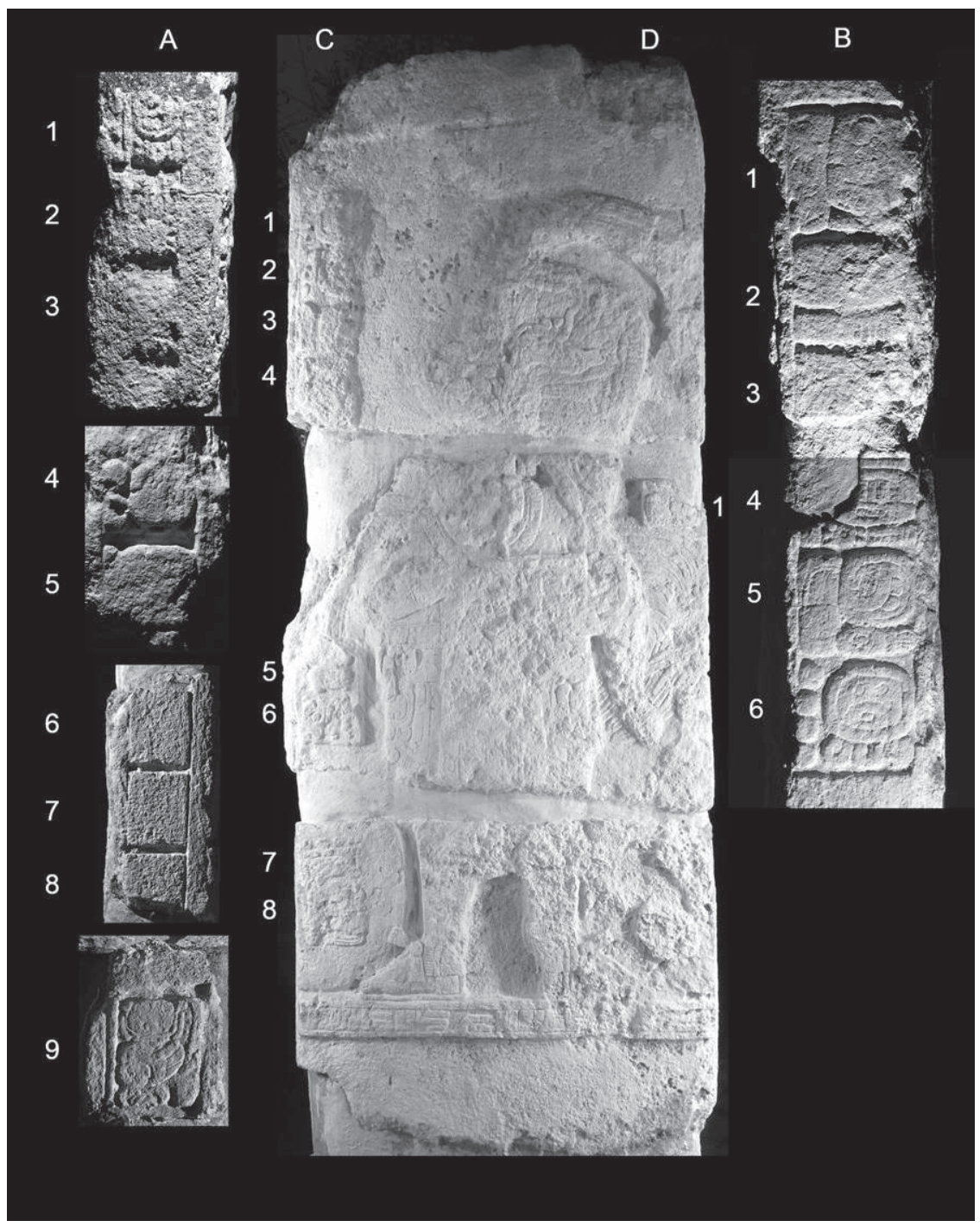

Fig. 12 - Fotografía de la Estela 66 y del texto localizado en sus lados derecho e izquierdo (fotografía R. Valencia, PAC). 
El juego de pelota como mecanismo de activación ritual

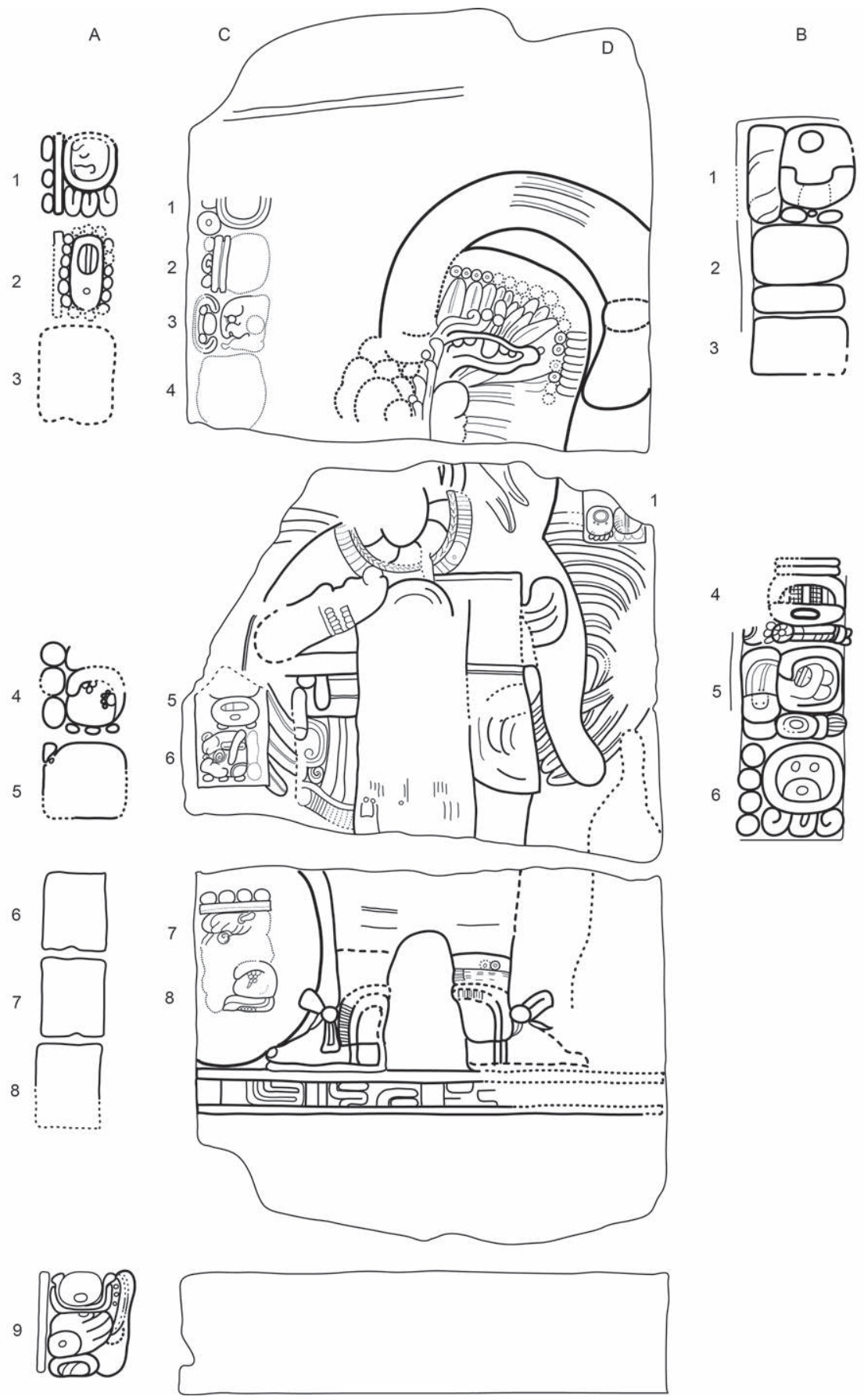

Fig. 13 - Dibujo de la Estela 66 y del texto localizado en sus lados derecho e izquierdo (dibujo R. Valencia, PAC). 
situaría dentro del periodo de gobierno de Yuhkno'm Took' K'awiil (Martin y Grube 2008, p. 112). Por tanto resulta muy probable que su incorporación dentro del juego de pelota se debiera a una remodelación del edificio. Debido a que los fragmentos no tienen el mismo grosor, se podría suponer que fueron recortados con posterioridad a ser dividida la estela, posiblemente con la intención de que pudieran ajustarse dentro de su posición de destino en el muro del juego de pelota. Asimismo, debido a sus medidas y a que hay un jeroglífico que representa al Glifo $5 \mathrm{C}$ de la Serie Lunar fuera de la secuencia normal (Figura 13: A9), el trozo que se ha colocado en la parte inferior de la estela pudiera no haber pertenecido en realidad al monumento (Martin 1998, p. 78), pero los otros tres sin duda pertenecían a la misma estela. Una característica importante del monumento es que posiblemente nunca fue utilizado, ya que presenta evidencias de no haber sido terminado. Podemos determinar esto sobre la base del hecho de que parte del texto en el lateral izquierdo presenta los cartuchos labrados y preparados para la inclusión de texto, que nunca se realizó (Figura 13: A6-A8).

La parte frontal de la Estela 66 (Figuras 12 y 13) muestra a un gobernante cuya identidad no puede verificarse usando el texto del monumento, pero que, como ya hemos indicado, debido a la fecha que aparece en su lado derecho, posiblemente se trate de Yuhkno'm Took' K'awiil. Algo que sí aporta el texto asociado al personaje es que poseía el título de kalo'mte' (Figura 13: C8), en lo que parece ser un título que denota la edad del gobernante al estar acompañado de un signo winikhaab. Como en otros ejemplos procedentes del área maya, al tratarse de monumentos descartados, la cara del personaje y parte de su cuerpo han sido obliterados (O’Neil 2013, p. 51), pero una buena parte de su parafernalia aparece con bastante detalle, lo cual nos permite identificarlo como un miembro de la realeza, pues lleva un gran tocado y una capa de largas plumas de quetzal. A su lado derecho aparece un bulto, que posiblemente sea ceremonial, y que además tiene un texto asociado que incluye un numeral 9 junto a un grupo de jeroglíficos ilegibles. Otra posibilidad es que se trate de una pelota, elemento asociado a la estructura donde fue recolocado el monumento, ya que en el texto localizado en la parte central del lado derecho del personaje (Figura 13: D1) podría leerse ba pi?-tz'i-la, baah pitz'iil, “primer jugador de pelota", aunque el texto no es del todo claro. Esta posibilidad, aunada al hecho de que el gobernante representado en la estela aparece vestido como un jugador de pelota, con un atuendo voluminoso y que le llega por encima de la cintura, parece denotar una conexión entre un monumento dedicado al juego de pelota y el propio edificio, lo que podría reforzar la idea de una activación ritual del espacio mediante el empleo de los trozos de monumento integrados en sus muros.

El juego de pelota de Calakmul aparece como escenario de varios encuentros entre dignatarios de distintas ciudades que mantenían relaciones políticas 
con la dinastía de los Kaanu'l, así como se aprecia en el panel que muestra a dos jugadores de pelota procedente de La Corona, localizado ahora en el Art Institute of Chicago y denominado como Elemento 13 por el proyecto La Corona (Stuart, Canuto y Barrientos 2015, p. 9): en él se indica que el juego se está llevando a cabo en Uxte' tuun Chi'knahb, nombres de espacios dentro de la ciudad o que designan al sitio de Calakmul en las inscripciones jeroglíficas (Stuart y Houston 1994, p. 28-29; Martin 1997, p. 852; Martin y Velásquez García 2017, p. 24). Podemos apreciar otro posible ejemplo de la aparición de esta estructura en inscripciones epigráficas en los paneles encontrados en Uxul, en la Estructura K2 (Grube y Delvendahl 2011), en los cuales aparecen señores de Calakmul jugando a la pelota, uno de los cuales sería Yuhkno'm Yich'aak K'ahk'. Como bien indican Helmke et al. (2015, p. 10), en estos paneles se muestra el juego de pelota de perfil y dentro del cuerpo aparece una cabeza con el signo k'an; los autores mencionan que este elemento aparece en un bloque hallado en el anexo de la Estructura XIII de Calakmul, con una inscripción jeroglífica que lo asocia con la expresión pitz, la cual se empleaba para designar al juego de pelota en tiempos prehispánicos en lengua maya ch'olana clásica (Figura 14a). Este bloque, designado como 541-5, apareció como parte del relleno constructivo del anexo de la Estructura XIII, junto a otros 21 bloques labrados, durante los trabajos realizados por el PAC en 1994 (Carrasco Vargas et al. 1996, p. 93). En él se puede leer el texto wa?-a-pi-tzi

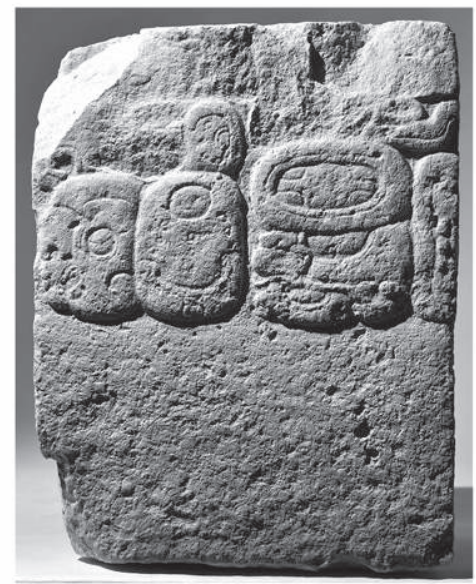

a

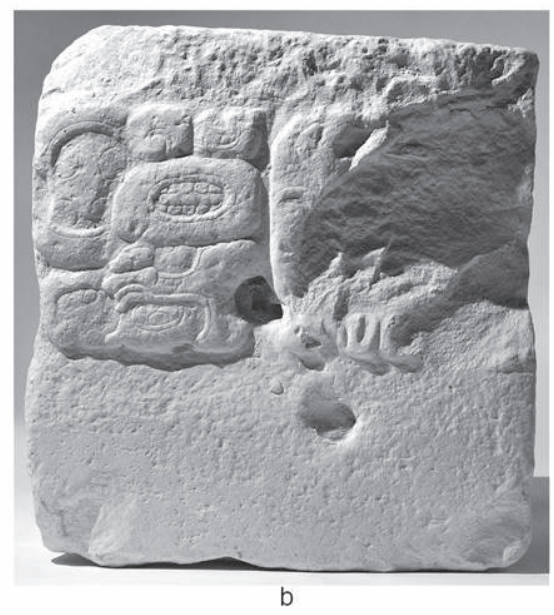

b

Fig. 14 - a. Bloque 541-5, procedente del anexo de la Estructura XIII de Calakmul, donde aparece el mismo conjunto jeroglífico que en los paneles de la Estructura K2 de Uxul (fotografía R. Valencia, PAC); b. Otro bloque localizado en el anexo de la Estructura XIII, donde aparece el mismo conjunto jeroglífico (fotografía R. Valencia, PAC). 
K'AN-na-TE'-NAL?, lo cual podría traducirse como "el juego de pelota [llamado] K'ante'nal". Otro bloque del mismo conjunto indica este mismo nombre una vez más (Figura 14b), escrito K'AN-na-TE'-NAL.

De manera significativa, otro de los bloques hallados dentro de este mismo conjunto de elementos tallados descartados en la Estructura XIII, muestra el juego de pelota de Calakmul (Figura 15a). En él aparecen unas escalinatas y el gobernante, posiblemente Yuhkno'm Ch'e'n (Martin 2008, p. 7-9), ataviado y arrodillado en una posición típica del juego de pelota. En el texto claramente se indica el Glifo Emblema del personaje, designándolo como uno de los miembros de la dinastía Kaanu'l. Una última posible representación del mismo juego de pelota, procedente del propio sitio de Calakmul, se ve en un bloque encontrado dentro del mismo conjunto del anexo de la Estructura XIII. En este puede apreciarse a dos personajes principales frente a una pelota, pero por desgracia el texto asociado es ilegible (Figura 15b).

Al analizar las características y los hallazgos realizados en el juego de pelota de Calakmul, resultan evidentes las similitudes que comparte con las canchas de Chactún, sobre todo en lo que se refiere a los fragmentos de la Estela 66 y a su recolocación en las esquinas de las banquetas a manera de marcadores. La escasez de este tipo de contextos en otras regiones del área maya, así como la proximidad geográfica entre ambos asentamientos y la interacción que muy posiblemente se pudo establecer entre ellos durante el Clásico, bien podrían

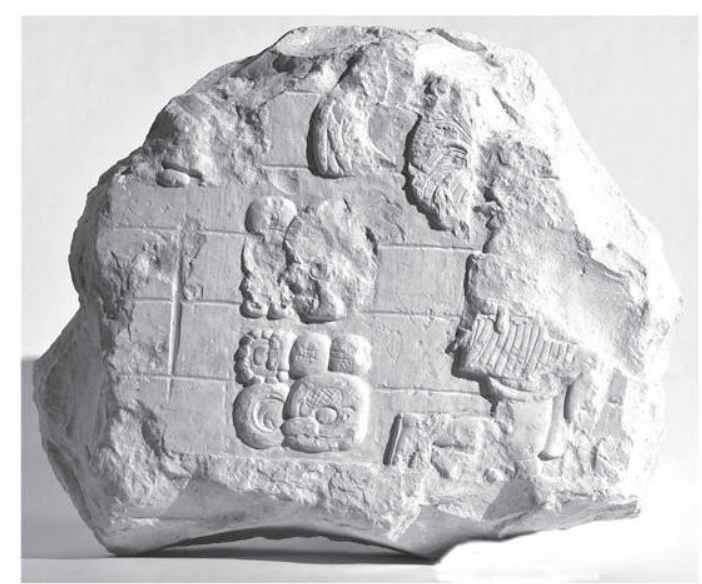

a

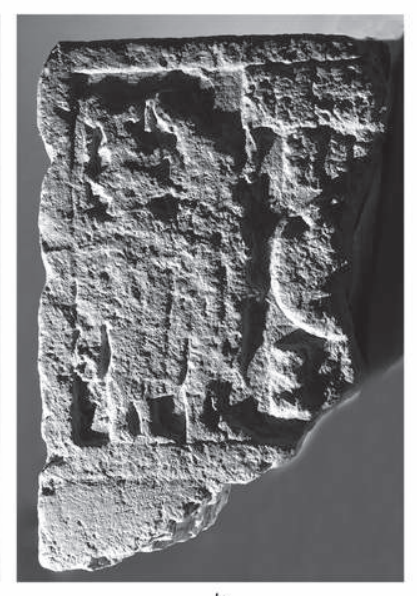

b

Fig. 15 - a. Bloque localizado en el anexo de la Estructura XIII de Calakmul, donde aparece representado un gobernante, posiblemente Yuhkno'm Ch'e'n, frente al juego de pelota de Calakmul (fotografía R. Valencia, PAC); b. Bloque localizado en el anexo de la Estructura XIII de Calakmul, donde aparecen representados dos personajes frente a una pelota (fotografía R. Valencia, PAC). 
interpretarse como indicadores de una práctica compartida en lo que se refiere al proceso de recolocación y su uso específico en espacios de gran relevancia ritual como lo es el juego de pelota.

Por otra parte, y en referencia a otros contextos de monolitos reutilizados en las canchas, existe evidencia que apunta al uso de monumentos lisos como material constructivo. En este caso, bloques lisos de grandes dimensiones, colocados como esquineros en las banquetas, han sido reportados en sitios como Becán (Ruppert y Denison 1943) y Cobá (Thompson, Pollock y Charlot 1932; Con Uribe 2000; Esparza Olguín 2016), así como en conjuntos arquitectónicos cercanos a Chactún, en la zona de transición entre las regiones Chenes y Río Bec (Šprajc et al. 2015). En todos estos casos los bloques de piedra colocados en una o más esquinas exhiben un tamaño mucho mayor al de las piedras que conforman el resto del cuerpo de las banquetas que delimitan la cancha, siendo su morfología muy similar a la de una estela o bien a la de un fragmento de esta.

Es preciso señalar la importancia que entre los mayas tenían las estelas lisas como objetos de culto y veneración, siendo erigidas desde épocas muy tempranas en distintos sitios como Palenque, Naranjo y Tikal. Monumentos de este tipo, en opinión de David Stuart (2010), se encontraban relacionados con diversas concepciones que los mayas tenían sobre el tiempo y los poderes sagrados del cielo, la tierra y el agua, así como mantenían un estrecho vínculo con objetos luminosos como hachuelas y espejos, al ser vistos como elementos de características similares, pero elaborados en una escala mayor.

En este estadio de la discusión resulta necesario mencionar que no todos los monumentos recolocados en el juego de pelota fueron usados como esquineros. Por ejemplo, uno de los escalones de la Escalera Jeroglífica de Naranjo, el decimotercero (Helmke y Awe 2016a, p. 3), fue puesto en el centro del juego de pelota de Ucanal (Graham 1978, p. 107; 1980, p. 152-154); dicho escalón posiblemente había sido expoliado junto con el resto de la escalinata durante la guerra en contra de Caracol (Martin 2000, p. 57-58). Por otra parte, durante las excavaciones en Moral-Reforma, efectuadas por el arqueólogo Daniel Juárez Cossío (2003), se realizó el hallazgo del Altar 1, fragmentado en dos secciones, que fueron colocadas en la parte central de las banquetas del juego de pelota (Figura 16).

Como puede apreciarse en estos últimos ejemplos, los monolitos recolocados se presentan en lugares específicos de la cancha, ya sea como esquineros o en el área central, tal y como si se trataran de marcadores que definen el espacio del juego y su parte media. Asimismo, esta colocación especial y el hecho de que la mayoría de los monumentos sean visibles, denota que su uso no fue aleatorio, ni desprovisto de algún otro propósito más allá de servir como material constructivo. En este sentido, y por medio del estudio de los textos jeroglíficos, se ha podido establecer que los espacios arquitectónicos y otros elementos vinculados con el juego de pelota estaban estrechamente relacionados con acciones que 


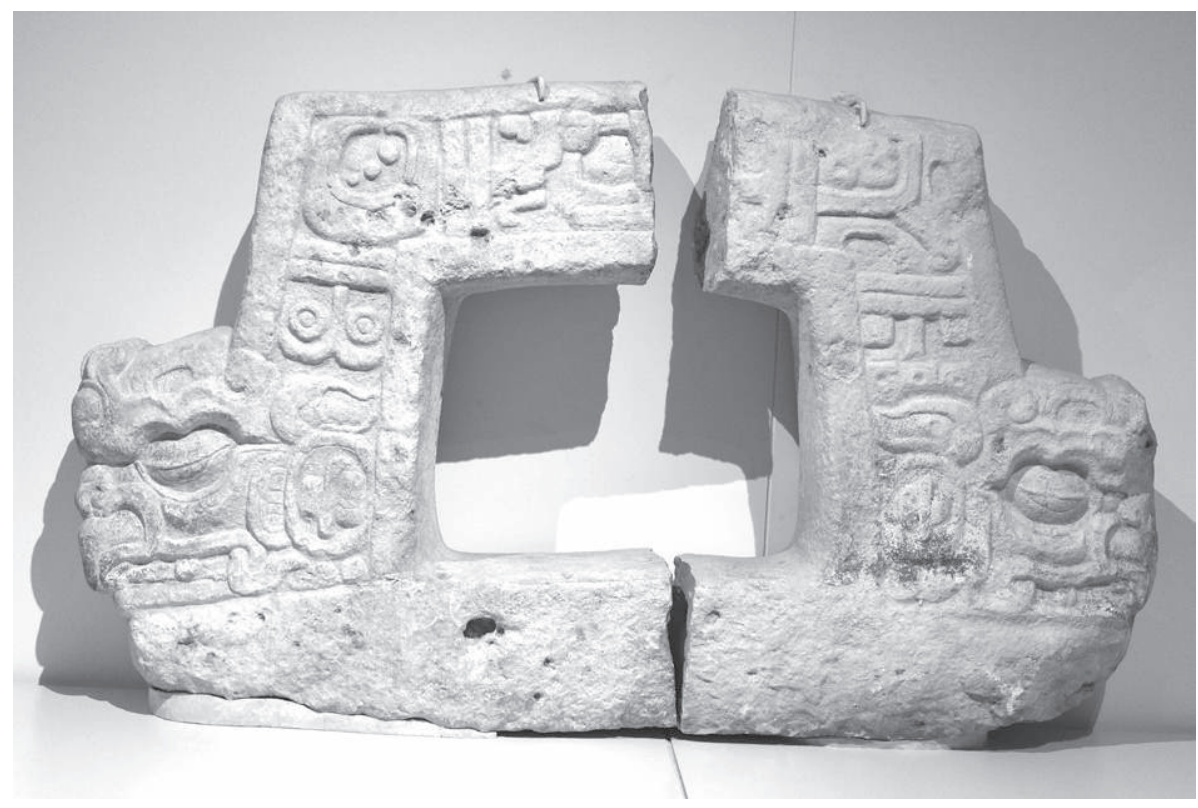

Fig. 16 - El Altar 1 de Moral-Reforma

(fotografía O. Esparza).

denotan su activación ritual. Así, expresiones como k'al (“atar”), yal (“arrojar”), jatz' ("golpear") y petaj ("hacerse redondo"), se encuentran registradas en las inscripciones de escalinatas, anillos y otros monumentos esculpidos que hacen referencia a la actividad de jugar a la pelota (y a ciertos eventos relacionados con el juego, como el sacrificio por rodamiento) en diversos sitios del área maya, tales como Oxkintok, Naranjo, El Perú, La Amelia y Yaxchilán, por mencionar algunos ejemplos (Graham 1982; Lacadena García-Gallo 1992; Grube 2004; Grube y Martin 2004; Zender 2004; Velásquez García 2015).

Por otra parte, existe una referencia interesante contenida en el Panel 7 de Cobá, monumento colocado en el talud de la estructura noreste del juego, y que exhibe una de las narrativas más extensas y tempranas del sitio. En su inscripción, se indica la formación o construcción de diversos monumentos, mediante la reiterada expresión PAT-TUN-ni ti-ZY3-na, pat $t u[u] n$ ti ...n, "la piedra se forma en [el juego de pelota]", que se relaciona con el conjunto

2. La clave ZY3, dentro del catálogo de Macri y Looper (2003), corresponde a un logograma indescifrado que hace referencia a la cancha del juego de pelota. Por otra parte, la expresión pat tuun no se encuentra referida únicamente en contextos relacionados con el juego de pelota. En realidad, se trata de un término asociado con la consagración de monumentos de piedra (Guenter 2005; Esparza Olguín y Pérez Gutiérrez 2009). 


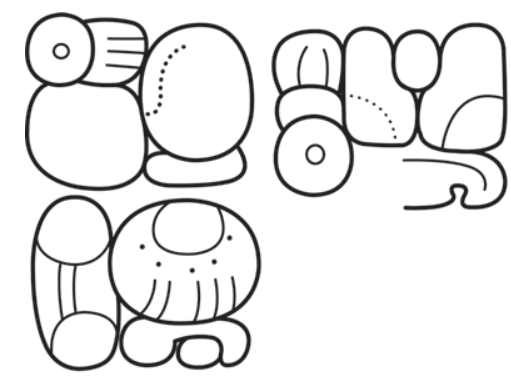

a

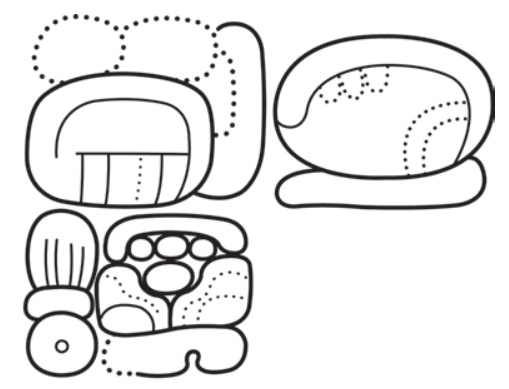

b

Fig. 17 - Las expresiones pat tuun registradas en el Panel 7 de Cobá:

a. PAT-TUN-ni ti-ZY3-na ko-ba-a, pat tu [u]n ti ...n kob[h]a',

"la piedra se forma en [el juego de pelota] de Kobha";

b. PAT-ja TUN-ni ti-u-ZY3-na, pa[h]t [a]j tu[u]n ti u ...n,

"la piedra fue formada en [el juego de pelota]"

(dibujos O. Esparza, Proyecto Cobá).

de monolitos que fueron colocados en los taludes de las dos estructuras que formalizan la cancha o bien con cierto número de ellos (Figura 17).

Resulta evidente que dicho conjunto debió ser integrado como parte culminante de la edificación, convirtiéndose en un componente fundamental de la consagración del juego de pelota (Figura 18, página siguiente). En este aspecto, podemos postular que los monumentos fragmentados y recolocados también eran referidos dentro de ese tipo de expresiones, tal vez como parte de un mismo programa escultórico.

\section{Discusión}

La reutilización de elementos constructivos u ornamentales, procedentes de distintos espacios arquitectónicos, con la finalidad de formar parte de una nueva construcción recibe a veces el término latino de spolia (Kinney 2011, p. 1). Este término se aplicaba originalmente a aquellos elementos, fueran del tipo que fueran, que se obtenían como botín de guerra y cuyo objetivo fundamental era el de humillar al vencido y establecer con claridad los derechos ganados por el vencedor (Kinney 2011, p. 4), tal y como pudo haber sido el caso del escalón hallado en Ucanal.

Esta reutilización puede tener dos posibles motivos. Por un lado, el objetivo pudo haber sido reutilizar materiales de alto valor, de difícil acceso o cuya elaboración fue muy compleja y requirió de mucho tiempo (Kinney 2011, p. 2). Benavente Motolinía ya indicaba que esa fue la principal motivación de la incorporación de elementos constructivos indígenas en las construcciones 


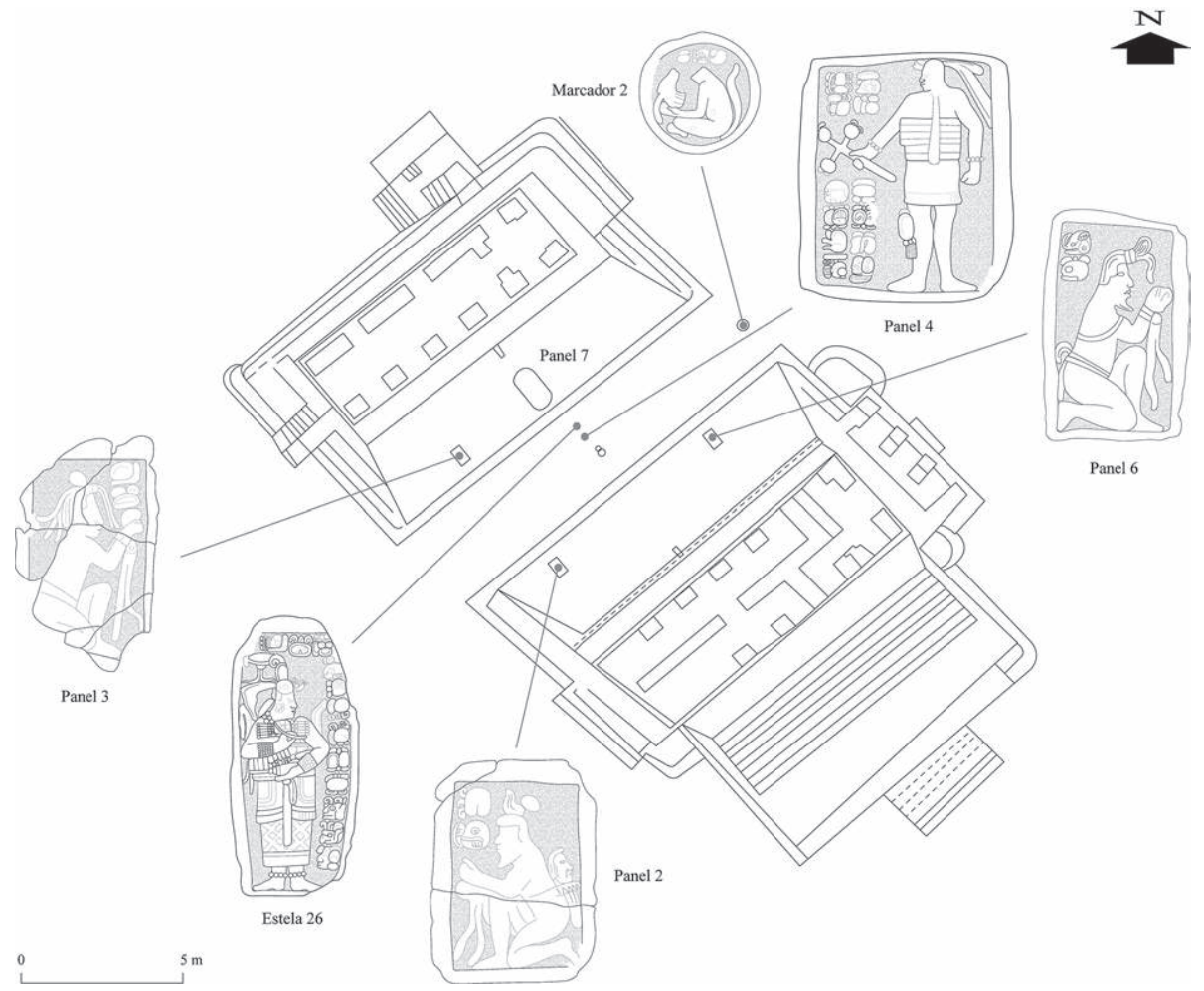

Fig. 18 - Conjunto de monumentos esculpidos asociados al juego de pelota del Grupo D de Cobá (dibujos de las plantas arquitectónicas María J. Con Uribe y José M. Ochoa Rodríguez; dibujo de los monumentos O. Esparza).

religiosas realizadas en América durante el siglo XVI, labor que fuera aprovechada de paso por los sacerdotes para destruir aquellos templos e imágenes que favorecían la idolatría entre los indios. El fraile indica lo siguiente:

Y con todo esto, siempre procuraron de guardar sus templos sanos y enteros, aunque después, yendo la cosa adelante, para hacer las iglesias comenzaron a echar mano de sus teocalme para sacar de ellos piedra y madera, y de esta manera quedaron desollados y derribados. Y los ídolos de piedra, de los cuales había infinitos, no solo escaparon quebrados y hechos pedazos, pero vinieron a servir de cimientos para las iglesias, y como había algunos muy grandes, venían lo mejor del mundo para cimiento de tan grande y santa obra. (Benavente Motolinía 2014, p. 31)

Pero también puede tener una motivación ideológica o religiosa, es decir, cargada de valor simbólico (Kinney 2011, p. 2). Uno de los ejemplos más famosos del uso de spolia fue durante la realización del arco del emperador Constantino en Roma, el cual reutiliza elementos iconográficos de monumentos 
pertenecientes a emperadores de otros tiempos, tales como Adriano, Trajano y Marco Aurelio, con los que él deseaba ser relacionado, con el fin de que quedara patente su derecho a gobernar, en un afán de traer el poder sustentado por los gobernantes del pasado al presente (Brilliant 2011, p. 169-171).

Existen otros ejemplos en los que la reutilización tiene una clara motivación religiosa, o hasta esotérica, ya que los elementos son reutilizados por los poderes que sus dueños originales, o aquellos que los van a reutilizar, les atribuyen teniendo estos generalmente un carácter apotropaico ${ }^{3}$ (Greenhalgh 2011, p. 86). Es decir, a ciertos elementos constructivos u ornamentales se les atribuyen características mágicas o esotéricas que proporcionan protección o bienestar a quien los emplea (ibid., p. 75).

Existen ejemplos de este uso apotropaico de la spolia procedentes de la antigüedad, tales como la reutilización de estatuas paganas romanas para la construcción de las murallas de protección de las ciudades de Asia Menor, entre las que se encuentran las de la ciudad de Ankara, en Turquía (James 1996, p. 16). En el basamento de los muros de las murallas de esta ciudad fueron colocadas estatuas de costado, con la finalidad de poder controlar el poder atribuido a las estatuas y de usar dicho poder para defender la ciudad.

Los datos referidos nos permiten apreciar las diversas motivaciones que tuvieron diferentes grupos humanos para reutilizar elementos escultóricos creados por sus antecesores, sin ser los mayas una excepción. En este último caso, el alto nivel simbólico de los monumentos pétreos los convirtió en piezas de un valor excepcional que, en ciertas ocasiones, debían ser integradas a los nuevos espacios construidos. En lo que se refiere a los juegos de pelota de Chactún, de Calakmul y de otros espacios similares, los contextos en que han sido encontrados los monolitos recolocados, o fragmentos de ellos, nos indican que existió más de una motivación para su inclusión dentro de dicho espacio ya sea como marcadores, ofrendas o bien como parte de un ritual de activación mediante el cual la cancha era preparada para llevar a cabo las ceremonias que debían llevarse a cabo en dicho espacio. La colocación de estos elementos pétreos dentro de los juegos de pelota obedece a un patrón específico, alejado del azar, que señala que su reutilización no tenía como finalidad la simple consolidación del edificio mediante el empleo de materiales descartados, sino que su motivación fue más bien ideológica. Como ya hemos indicado con anterioridad, las estelas y otros monumentos esculpidos mayas hechos de piedra eran objetos animados dentro de la cosmovisión maya (Stuart 2010, p. 288) y la utilización de estos objetos dentro de estructuras arquitectónicas parece señalar que dicha animación era transferible al propio edificio que los recibía. Al parecer este poder

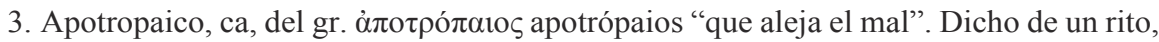
de un sacrificio, de una fórmula, etc., que, por su carácter mágico, se cree que aleja el mal o propicia el bien (Diccionario de la Real Academia Española). 
inherente de los monumentos esculpidos, empleados durante la celebración de los ciclos calendáricos que para los gobernantes mayas eran tan importantes, era transferible y reutilizable para conferir algo de dicho poder a los espacios en los que estos objetos eran utilizados.

Resulta evidente que nuestro conocimiento sobre el proceso de la recolocación de monumentos en el área maya, particularmente en la región del sur del Campeche, se ha ido acrecentando en los últimos años, siendo necesario el estudio detallado de una mayor cantidad de sitios y contextos para elaborar planteamientos cada vez más precisos sobre este apasionante tema. ${ }^{*}$

* Manuscrit reçu en juillet 2018, accepté pour publication en juillet 2019.

Agradecimientos - En este espacio queremos expresar toda nuestra gratitud al Dr. Ivan Šprajc, director del Proyecto de Reconocimiento Arqueológico en el Sureste del Estado de Campeche, sin cuya investigación pionera en el área de la Reserva de la Biósfera de Calakmul hubiera sido imposible el descubrimiento de Chactún y el estudio de sus monumentos. Mucha de la información contenida en el presente artículo procede de los trabajos arqueológicos y epigráficos efectuados dentro de dicho proyecto durante la temporada de campo del año 2013. De igual forma agradecemos al arqueólogo Ramón Carrasco Vargas por brindarnos toda la información relacionada con la excavación de la Estructura XI de Calakmul y el hallazgo de la Estela 66. Finalmente, nuestra gratitud a los lectores externos cuyo trabajo de revisión fue fundamental para la elaboración de un mejor escrito.

\section{Referencias citadas}

ANDREws George F.

1995 Architectural Survey at Calakmul 1994/1995, University of Oregon, Oregon. Benavente Motolinía Toribio de (fray)

2014 Historia de los indios en la Nueva España, Real Academia Española, Madrid. BRILLIANT, Richard

2011 "Authenticity and Alienation", in Richard Brilliant y Dale Kinney (eds), Reuse Value. Spolia and Appropriation in Art and Architecture from Constantine to Sherrie Levine, Ashgate, Surrey y Burlington, p. 167-177.

Carrasco Vargas Ramón, Sylviane Boucher, Claude Baudez, Jean Pierre Courau, Anne Dowd, Marc Wolf, Emily González, Simon Martin, Valeria García, Renata Schneider, Gloria SÁnchez, Rosalía Carrillo, Armando Paul, Nidia Rojas, Melissa Brook

1996 Proyecto Arqueológico de la Biósfera de Calakmul, Vol. I, INAH, México. Con URIBE María José

2000 “El juego de la pelota en Cobá, Quintana Roo”, Arqueología (Mexico), 23, p. 27-50. 
El juego de pelota como mecanismo de activación ritual

Esparza Olguín Octavio Q.

2012 Las escaleras jeroglificas de El Resbalón, Quintana Roo. Estudio de un conjunto de inscripciones mayas del Clásico Temprano, Tesis de Maestría, Posgrado en Estudios Mesoamericanos, Facultad de Filosofía y Letras, Instituto de Investigaciones Filológicas, Universidad Nacional Autónoma de México, México.

2015 "Documentación de los monumentos esculpidos", in Ivan Šprajc (ed.), Exploraciones arqueológicas en Chactún, Campeche, México, Založba ZRC (Prostor, kraj, čas 7), Ljubljana, p. 41-84.

2016 Estudio de los monumentos esculpidos de Cobá, Quintana Roo, y su contexto arqueológico, Tesis de Doctorado, Posgrado en Estudios Mesoamericanos, Facultad de Filosofía y Letras, Instituto de Investigaciones Filológicas, Universidad Nacional Autónoma de México, México.

Esparza Olguín Octavio Q. y Vania E. Pérez Gutiérrez

2009 "Archaeological and epigraphic studies in Pol Box, Quintana Roo", The PARI Journal, 9 (3), p. 1-16.

GonZÁLEz Emily

1996 "La encrucijada de la Estructura XIII de Calakmul, Campeche", in Informe técnico del Proyecto arqueológico de la biósfera de Calakmul, subproyectos y estudios especiales, INAH Mérida, Yucatán, p. 70-78.

Graham Ian

1978 Corpus of Maya Hieroglyphic Inscriptions, vol. 2, part. 2. Naranjo, Chunhuiz, Xunantunich, Peabody Museum of Archaeology and Ethnology, Cambridge.

1980 Corpus of Maya Hieroglyphic Inscriptions, vol. 2, part. 3. Ixkun, Ucanal, Ixtutz, Naranjo, Peabody Museum of Archaeology and Ethnology, Cambridge.

1982 Corpus of Maya Hieroglyphic Inscriptions, vol. 3, part. 3. Yaxchilán, Peabody Museum of Archaeology and Ethnology, Cambridge.

Greenhalgh Michael

2011 "Spolia: a definition in ruins", in Richard Brilliant y Dale Kinney (eds), Reuse Value. Spolia and Appropriation in Art and Architecture from Constantine to Sherrie Levine, Ashgate, Surrey y Burlington, p. 75-95.

GruBE Nikolai

2004 "La historia dinástica de Naranjo, Petén”, Beitrage zur Allgemeinen und Vergleichenden Archaologie, 24, p. 195-213.

Grube Nikolai y Kai Delvendahl

2011 "Los jugadores de pelota de Uxul, Campeche. Nuevos hallazgos", Arqueología Mexicana, 112, p. 64-69.

Grube Nikolai y Simon Martin

2004 "Patronage, Betrayal, and revenge: diplomacy and politics in the Eastern Maya Lowlands", in Maya Workshop Foundation (Austin), Notebook for the XXVIIIth Maya Hieroglyphic Forum at Texas, March 2004, University of Texas at Austin, Austin, p. 1-95.

Guenter Stanley

2005 "La corona find sheds light on site Q mystery", The PARI Journal, 6, p. 14-16. 
HAmmond Norman y Matthew R. Bово

1994 "Pilgrimage's last mile: late Maya monument veneration at La Milpa, Belize", World Archaeology, 26, p. 19-34.

Hammond Norman y Gair TouRTEllot

2006 "Una segunda oportunidad: fundación y re-fundación en la ciudad maya de la época clásica de La Milpa, Belice", in Ma. Josefa Iglesias Ponce de León, Rogelio Valencia Rivera y Andrés Ciudad Ruiz (eds), Nuevas ciudades, nuevas patrias. Fundación y relocalización de ciudades en Mesoamérica y el Mediterráneo antiguo, Sociedad Española de Estudios Mayas, Madrid, p. 93-104.

Helmke Christophe y Jaime J. Awe

2016a "Death becomes her: an analysis of Panel 3, Xunantunich, Belize", The PARI Journal, 16 (4), p. 1-14.

$2016 \mathrm{~b}$ "Sharper than a serpent's tooth: a tale of the Snake-Head Dynasty as recounted on Xunantunich Panel 4", The PARI Journal, 17 (4), p. 1-22.

Helmke Christophe, Christopher R. Andres, Shawn G. Morton, Gab D. Wrobel

2015 "For love of the game: the ballplayer panels of Tipan Chen Uitz in light of Late Classic athletic hegemony", The PARI Journal, 16 (2), p. 1-30.

Houston Stephen y David StuarT

1998 "The ancient Maya self: personhood and portraiture in the Classic Period", RES: Anthropology and Aesthetics, 33, p. 73-101.

Houston Stephen, Karl Taube, Ray Matheny, Deanne Matheny, Zachary Nelson, Gene Ware y Cassandra Mesick

2005 "The pool of the rain god: an early stuccoed Altar at Aguacatal, Campeche, Mexico", Mesoamerican Voices, 2 (2005), p. 37-62.

JAMES Liz

1996 "Pray not to fall into temptation and be on your guard: pagan statues in Christian Constantinople", Gesta, 35, p. 12-20.

JuÁRez Cossío Daniel

2003 "Moral-reforma: en la senda de Xibalbá", Arqueología Mexicana, 11 (61), p. 38-43.

KinNey Dale

2011 "Introduction”, in Richard Brilliant y Dale Kinney (eds), Reuse Value. Spolia and Appropriation in Art and Architecture from Constantine to Sherrie Levine, Ashgate, Surrey y Burlington, p. 1-11.

LaCAdEna García-Gallo Alfonso

1992 "El anillo jeroglífico del Juego de Pelota de Oxkintok", in Justin Kerr y Barbara Kerr (eds), Oxkintok, Vol. 4. Misión Arqueológica de España en México [Proyecto Oxkintok año 1990], Instituto de Conservación y Restauración de Bienes Culturales, Madrid, p. 177-184.

2011 "Historia y ritual dinásticos en Machaquilá (Petén, Guatemala)", Revista Española de Antropología Americana, 41 (1), p. 205-240.

MACRI Martha y Matthew LOOPER

2003 The New Catalog of Maya Hieroglyphs, Vol. 1. The Classic Period Inscriptions, University of Oklahoma Press, Norman. 
El juego de pelota como mecanismo de activación ritual

MARTin Simon

1997 "The painted king list: a commentary on codex-style dynastic vases", in Justin Kerr y Barbara Kerr (eds), The Maya Vase Book, Vol. 5, Kerr Associates, New York, p. 847-867.

1998 "Report on epigraphic fieldwork at Calakmul: 1995-1998", in Ramón Carrasco Vargas (ed.), Proyecto Arqueológico Calakmul. Informe de los trabajos arqueológicos de la temporada 1997-1998, INAH, México, p. 72-122.

2000 "At the periphery: the movement, modification and re-use of early monuments in the environs of Tikal", in Pierre Robert Colas, Kai Delvendahl, Marcus Kuhnert y Annette Schubart (eds), The Sacred and the Profane. Architecture and Identity in the Southern Maya Lowlands, Verlag Anton Saurwein (Acta Mesoamericana, 10), Markt Schwaben, p. 51-62.

2008 "Reading Calakmul: epigraphy of the Proyecto arqueológico de Calakmul 19942008", trabajo presentado en la VI Mesa Redonda de Palenque [Palenque, México, 16-21 noviembre 2008].

MARTIN Simon y Nikolai GrubE

2002 Crónica de los reyes y reinas mayas. La primera historia de las dinastías mayas, Planeta, México.

2008 Chronicle of the Maya Kings and Queens, Thames \& Hudson, London.

Martin Simon y Erik Velásquez García

2017 "Polities and places: tracing the toponyms of the Snake Dynasty", The PARI Journal, 17 (2), p. 23-33.

Morley Sylvanus G.

1927 “Archaeology”, Carnegie Institution of Washington Year book, 26, p. 231-240.

2006 "The Four Coba Expeditions", in John M. Weeks y Jane A. Hill (eds), The Carnegie Maya. The Carnegie Institution of Washington Maya Research Program, 1913-1957, University Press of Colorado, Boulder, p. 554-555.

Nalda Hernández Enrique (ed.)

2004 Los cautivos de Dzibanché, Consejo Nacional para la Cultura y las Artes, Instituto Nacional de Antropología e Historia, México.

O'NEIL Megan

2013 "Marked faces, displaced bodies: monument breakage, and reuse among the Classic Period Maya”, in Stacy Boldrick, Leslie Brubaker y Richard Clay (eds), Striking Images. Iconoclasms Past and Present, Ashgate Publishing Company, Farnham, p. 47-63.

Pollock Harry

1932 "Description of the ruins", in A Preliminary Study of the Ruins of Coba, Quintana Roo, México, Carnegie Institution of Washington (Publicación, 424), Washington (DC), p. 15-130.

RuPPERT Karl y John H. Denison

1943 Archaeological reconnaissance in Campeche, Quintana Roo, and Peten, Carnegie Institution of Washington (Publicación, 543), Washington (DC).

SATTERTHWAITE Linton

1986 The problem of abnormal stela placements at Tikal and elsewhere, University Museum, University of Pennsylvania (Tikal Reports, 3), Philadelphia. 
ŠrraJC Ivan (ed.)

2015 Exploraciones arqueológicas en Chactún, Campeche, México, Založba ZRC (Prostor, kraj, čas 7), Ljubljana.

Šrrajc Ivan, Octavio Q. Esparza Olguín, Arianna CAmpiani, Atasta Flores Esquivel, Aleš Marsetič y Joseph W. Ball

2015 "Chactún, Tamchén y Lagunita: primeras incursiones arqueológicas a una

StUART David región ignota", Arqueología Mexicana, 23 (136), p. 20-25.

1996 "Kings of stone: a consideration of stelae in ancient Maya ritual and representation", RES: Anthropology and Aesthetics, 29 (1), p. 148-171.

2010 "Shining stones: observations on the ritual meaning of early Maya stelae", in Julia Guernsey, John E. Clark y Bárbara Arroyo (eds), The Place of Stone Monuments. Context, Use, and Meaning in Mesoamerica's Preclassic Transition, Dumbarton Oaks Research Library and Collection (Pre-Columbian symposia and colloquia), Washington (DC), p. 283-298.

Stuart David, Marcello A. Canuto y Tomás Barrientos

2015 "The nomenclature of La Corona sculpture", La Corona Notes, 1 (2), p. 1-9.

Stuart David y Stephen Houston

1994 Classic Maya Place Names, Dumbarton Oaks Research Library and Collection (Studies in Pre-Columbian art \& archaeology, 33), Washington (DC).

Thompson J. Eric S., Harry E. D. Pollock y Jean Charlot

1932 A Preliminary Study of the Ruins of Coba, Quintana Roo, México, Carnegie Institution of Washington (Publicación, 424), Washington (DC).

Tsukamoto Kenichiro

2005 "Un estudio sobre la organización espacial del antiguo asentamiento maya El Resbalón, Quintana Roo", Estudios de Cultura Maya, 26, p. 41-66.

VELÁSQUEZ García Erik

2015 "El juego de pelota entre los mayas del periodo Clásico (250-900 d. C.)", in María Teresa Uriarte (ed.), El juego de pelota mesoamericano. Temas eternos nuevas aproximaciones, Universidad Nacional Autónoma de México, Instituto de Investigaciones Estéticas, México, p. 251-326.

WALTERS Rex

1978 Informe de trabajo desarrollado en Resbalón, Q. R., mecanuscrito.

ZENDER Marc U.

2004 “Glyphs for 'Handspan' and 'Strike' in Classic Maya ballgame texts", The PARI Journal, 4 (4), p. 1-9. 